\title{
Front Matter: Volume 8421
}

, "Front Matter: Volume 8421," Proc. SPIE 8421, OFS2012 22nd International Conference on Optical Fiber Sensors, 842101 (17 October 2012); doi: $10.1117 / 12.2010129$

SPIE Event: OFS2012 22nd International Conference on Optical Fiber Sensor, 2012, Beijing, China 


\title{
PROCEEDINGS OF SPIE
}

\section{2nd International Conference on Optical Fiber Sensors}

\author{
Yanbiao Liao \\ Wei Jin \\ David D. Sampson \\ Ryozo Yamauchi \\ Youngjoo Chung \\ Kentaro Nakamura \\ Yunjiang Rao \\ Editors
}

\section{5-19 October 2012 \\ Beijing, China}

Organised by

Tsinghua University (China) • The Hong Kong Polytechnic University (Hong Kong) • BeiHang University (China) • Harbin Engineering University (China) • Wuhan University of Technology (China)

Cooperating Organisations

Chinese Optical Society • National Natural Science Foundation of China • SPIE • The Optical Society of America • IEEE Photonics Society • The Australian Optical Society • The Optical Society of Korea $\cdot$ The Optical Society of Japan

Published by

SPIE

Part One of Three Parts

Volume 8421 
The papers included in this volume were part of the technical conference cited on the cover and title page. Papers were selected and subject to review by the editors and conference program committee. Some conference presentations may not be available for publication. The papers published in these proceedings reflect the work and thoughts of the authors and are published herein as submitted. The publisher is not responsible for the validity of the information or for any outcomes resulting from reliance thereon.

Please use the following format to cite material from this book:

Author(s), "Title of Paper," in OFS2012 22nd International Conference on Optical Fiber Sensors, edited by Yanbiao Liao, Wei Jin, David D. Sampson, Ryozo Yamauchi, Youngjoo Chung,

Kentaro Nakamura, Yunjiang Rao, Proceedings of SPIE Vol. 8421 (SPIE, Bellingham, WA, 2012) Article CID Number.

ISSN: 0277-786X

ISBN: 9780819491039

Published by

SPIE

P.O. Box 10, Bellingham, Washington 98227-0010 USA

Telephone +1 3606763290 (Pacific Time) · Fax +1 3606471445

SPIE.org

Copyright (c) 2012, Society of Photo-Optical Instrumentation Engineers.

Copying of material in this book for internal or personal use, or for the internal or personal use of specific clients, beyond the fair use provisions granted by the U.S. Copyright Law is authorized by SPIE subject to payment of copying fees. The Transactional Reporting Service base fee for this volume is $\$ 18.00$ per article (or portion thereof), which should be paid directly to the Copyright Clearance Center (CCC), 222 Rosewood Drive, Danvers, MA 01923. Payment may also be made electronically through CCC Online at copyright.com. Other copying for republication, resale, advertising or promotion, or any form of systematic or multiple reproduction of any material in this book is prohibited except with permission in writing from the publisher. The CCC fee code is 0277-786X/12/\$18.00.

Printed in the United States of America.

Publication of record for individual papers is online in the SPIE Digital Library.

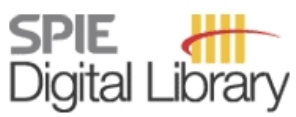

SPIEDigitalLibrary.org

Paper Numbering: Proceedings of SPIE follow an e-First publication model, with papers published first online and then in print and on CD-ROM. Papers are published as they are submitted and meet publication criteria. A unique, consistent, permanent citation identifier (CID) number is assigned to each article at the time of the first publication. Utilization of CIDs allows articles to be fully citable as soon as they are published online, and connects the same identifier to all online, print, and electronic versions of the publication. SPIE uses a six-digit CID article numbering system in which:

- The first four digits correspond to the SPIE volume number.

- The last two digits indicate publication order within the volume using a Base 36 numbering

system employing both numerals and letters. These two-number sets start with 00, 01, 02, 03, 04,

05, 06, 07, 08, 09, OA, OB ... 0Z, followed by 10-1Z, 20-2Z, etc.

The CID Number appears on each page of the manuscript. The complete citation is used on the first page, and an abbreviated version on subsequent pages. Numbers in the index correspond to the last two digits of the six-digit CID Number. 


\section{Contents}

xliii Conference Committee

xlix Introduction

\section{Part 1}

FIBER OPTIC GYRO I: 35 ANNIVERSARY WORKSHOP

842102 Fiber optic gyros past, present, and future (Invited Paper) [8421-97]

G. A. Pavlath, Northrop Grumman Corp. (United States)

842104 The fiber-optic gyroscope: actually better than the ring-laser gyroscope? (Invited Paper) [8421-575]

H. C. Lefevre, iXBlue SAS (France)

842105 Fiber optic gyro R\&D at Beihang University (Invited Paper) [8421-577]

C. Zhang, N. Song, L. Li, J. Jin, D. Yang, H. XU, X. Pan, X. Wang, BeiHang Univ. (China)

FIBER OPTIC GYRO II: 35 ANNIVERSARY WORKSHOP

842106 Fiber optic gyros in a high-performance, high-reliability inertial reference unit for commercial satellites (Invited Paper) [8421-546]

S. Sanders, A. Taranta, S. Mosor, M. Alden, L. Hendry, R. DeMaio, N. Giere, J. Sewell, Honeywell International Inc. (United States)

842107 Interferometric closed loop fiber optical gyroscopes for commercial and space applications (Invited Paper) [8421-61]

Y. N. Korkishko, V. A. Fedorov, V. E. Prilutskii, V. G. Ponomarev, I. V. Morev, S. M. Kostritskii,

A. I. Zuev, V. K. Varnakov, RPC Optolink, Ltd. (Russian Federation)

FIBER OPTIC GYRO III: 35 ANNIVERSARY WORKSHOP

842109 Resonator fiber optic gyro progress including observation of navigation grade angle random walk (Invited Paper) [8421-700]

L. K. Strandjord, T. Qiu, J. Wu, T. Ohnstein, G. A. Sanders, Honeywell International Inc. (United States)

8421 OA Resonator fiber optic gyro with bipolar digital Serrodyne Modulation Scheme (Invited Paper) [8421-650]

X. Wang, M. Kishi, Z. He, K. Hotate, The Univ. of Tokyo (Japan) 
8421 OB Improving fiber optic gyroscope performance using a laser and photonic-bandgap fiber (Invited Paper) [8421-701]

S. Lloyd, S. Fan, M. J. F. Digonnet, Stanford Univ. (United States)

8421 OC Truly single-mode polarization maintaining hollow core PCF [8421-399]

J. K. Lyngsø, C. Jakobsen, H. R. Simonsen, J. Broeng, NKT Photonics A/S (Denmark)

8421 OD Polarization maintaining photonic crystal fiber IFOG [8421-564]

Y. Yang, M. Ye, W. Duan, BeiHang Univ. (China); W. Jin, BeiHang Univ. (China) and The Hong Kong Polytechnic Univ. (Hong Kong, China); C. Liu, S. Ruan, Shenzhen Univ. (China)

SPECIAL WORKSHOP ON INDUSTRIAL PROGRESS, COMMERCIAL SYSTEMS, AND FIELD TESTS I

8421 OE Optical coherence tomography and optical smart sensing (Invited Paper) [8421-526] B. H. Lee, Gwangju Institute of Science and Technology (Korea, Republic of); W. J. Choi, Korea Basic Science Institute (Korea, Republic of); E. J. Min, K. S. Park, Y. H. Kim, Gwangju Institute of Science and Technology (Korea, Republic of)

8421 OF Fiber optic sensors shine bright: industrial applications where FOS bring differentiated performance/value (Invited Paper) [8421-600]

A. D. Kersey, CiDRA (United States)

SPECIAL WORKSHOP ON INDUSTRIAL PROGRESS, COMMERCIAL SYSTEMS, AND FIELD TESTS II

$8421 \mathrm{OH} \quad$ Fiber-optic strain sensors are making the leap from lab to industrial use: reliability and validation as precondition for standards (Invited Paper) [8421-590]

W. R. Habel, Bundesanstalt für Materialforschung und -prüfung (Germany)

84210 Fiber optic sensors and their applications on structural health monitoring in South Korea (Invited Paper) [8421-581]

I.-B. Kwon, K.-S. Choi, Korea Research Institute of Standards and Science (Korea, Republic of)

8421 0J Research on optic fiber sensing engineering technology (Invited Paper) [8421-582]

D. Jiang, C. Zhou, M. Yang, S. Li, H. Wang, Wuhan Univ. of Technology (China)

SPECIAL WORKSHOP ON INDUSTRIAL PROGRESS, COMMERCIAL SYSTEMS, AND FIELD TESTS III

8421 OK Raman sensors and their applications (Invited Paper) [8421-324]

A. H. Hartog, Schlumberger Fiber-Optic Technology Ctr. (United Kingdom) 
8421 OL Recent progress in distributed optical fiber Raman sensors (Invited Paper) [8421-588] Z. Zhang, S. Jin, J. Wang, China Jiliang Univ. (China) and Hangzhou Optoelectronic Technology Co. Ltd. (China); Y. Li, H. Gong, China Jiliang Univ. (China); X. Yu, H. Liu, China Jiliang Univ. (China) and Hangzhou Optoelectronic Technology Co. Ltd. (China); Y. Jin, J. Kang, C. Li, China Jiliang Univ. (China); W. Zhang, Z. Sun, China Jiliang Univ. (China) and Hangzhou Optoelectronic Technology Co. Ltd. (China); C. Zhao, X. Dong, China Jiliang Univ. (China)

SPECIAL WORKSHOP ON INDUSTRIAL PROGRESS, COMMERCIAL SYSTEMS, AND FIELD TESTS IV

842100 Development of fiber-optic current sensing technology for electric power systems (Invited Paper) [8421-583]

K. Kurosawa, Tokyo Electric Power Co. (Japan)

8421 OP Fiber optic acoustic sensing (Invited Paper) [8421-578]

C. Kirkendall, U.S. Naval Research Lab. (United States)

$84210 Q \quad$ Recent progress toward fiber optic hydrophone research, application and commercialization in China (Invited Paper) [8421-585]

Y. Hu, Z. Hu, H. Luo, L. Ma, S. Xiong, National Univ. of Defense Technology (China) and National and Provincial United Lab. of Fiber Information Engineering Technology (China); Y. Liao, M. Zhang, Tsinghua Univ. (China)

8421 OR Fiber optical sensor trends in the energy field (Invited Paper) [8421-596]

M. Willsch, T. Bosselmann, M. Villnow, Siemens AG (Germany); W. Ecke, Institut für Photonische Technologien e.V. (Germany)

\section{PHYSICAL AND MECHANICAL SENSORS I}

8421 OT Development of nano-strain-resolution fiber optic quasi-static strain sensors for geophysical applications (Invited Paper) [8421-369]

Z. He, Q. Liu, T. Tokunaga, The Univ. of Tokyo (Japan)

8421 OU Compact flexural disc accelerometers based on optical microfiber [8421-73] G. Y. Chen, Univ. of Southampton (United Kingdom); X. Zhang, National Univ. of Defense Technology (China); T. Lee, G. Brambilla, T. P. Newson, Univ. of Southampton (United Kingdom)

$84210 \mathrm{~V}$ A passive frequency noise insensitive fiber strain sensor using post processing [8421-106] T. T.-Y. Lam, The Australian National Univ. (Australia); M. B. Gray, National Measurement Institute (Australia); D. A. Shaddock, D. E. McClelland, J. H. Chow, The Australian National Univ. (Australia)

8421 OW Rocking filter in microstructured fiber for high resolution hydrostatic pressure measurements [8421-149]

A. Anuszkiewicz, G. Statkiewicz-Barabach, T. Borsukowski, J. Olszewski, T. Martynkien,

D. Kowal, W. Urbanczyk, Wroclaw Univ. of Technology (Poland); P. Mergo, M. Makara,

K. Poturaj, Maria Curie-Sklodowska Univ. (Poland); T. Geernaert, F. Berghmans,

H. Thienpont, Vrije Univ. Brussel (Belgium) 
$84210 X \quad$ All-fiber acceleration sensor with temperature self-compensation [8421-215]

T. Zhu, Q. Zhang, L. Shi, Y. Hou, Chongqing Univ. (China); X. Bao, Univ. of Ottawa (Canada)

MICRO- AND NANO-STRUCTURED FIBER SENSORS I

8421 OY Temperature compensated, humidity insensitive, high- $\mathrm{T}_{\mathrm{g}}$ TOPAS FBGs for accelerometers and microphones (Invited Paper) [8421-571]

A. Stefani, Technical Univ. of Denmark (Denmark); W. Yuan, Singapore Institute of Manufacturing Technology (Singapore); C. Markos, Univ. of Patras (Greece);

H. K. Rasmussen, Technical Univ. of Denmark (Denmark); S. Andresen, R. Guastavino,

F. K. Nielsen, Brüel \& Kjaer Sound \& Vibration Measurement A/S (Denmark); B. Rose,

O. Jespersen, N. Herholdt-Rasmussen, Ibsen Photonics A/S (Denmark); O. Bang, Technical

Univ. of Denmark (Denmark)

$84210 Z$ Temperature-independent pressure sensor using triangular-shape of suspended-core fiber [8421-46]

M. I. Zibaii, S. Nouri, J. Sadeghi, H. Latifi, Shahid Beheshti Univ. (Iran, Islamic Republic of);

P. A. S. Jorge, INESC Porto (Portugal); K. Schuster, J. Kobelke, Institute of Photonic

Technology (Germany); O. Frazão, INESC Porto (Portugal)

842110 Discrimination of chemical vapor and temperature effects by using a polarizationmaintaining photonic crystal fiber interferometer [8421-63]

N. Jun, H.-J. Kim, Hanyang Univ. (Korea, Republic of); S. B. Lee, Korea Institute of Science and Technology (Korea, Republic of); Y.-G. Han, Hanyang Univ. (Korea, Republic of)

842111 Femtosecond laser microstructuring through optical fibre end faces: inscription of surface gratings and sub-surface splitters [8421-109]

G. C. B. Lee, Aston Univ. (United Kingdom); K. Kalli, C. Koutsides, Cyprus Univ. of Technology (Cyprus); M. Komodromos, Frederick Univ. (Cyprus); K. Sugden, Aston Univ. (United Kingdom)

842112 Compact optical microfiber components based on small size piezoelectric ceramic transducer [8421-152]

X. Zhang, National Univ. of Defense Technology (China); G. Chen, Univ. of Southampton

(United Kingdom); Z. Song, National Univ. of Defense Technology (China); M. Belal,

E. Koukharenko, G. Brambilla, T. P. Newson, Univ. of Southampton (United Kingdom)

\section{DISTRIBUTED SENSING I}

842113 Fast and distributed Brillouin time domain analysis of optical fibers (Invited Paper) [8421-375]

Y. Peled, A. Motil, L. Yaron, M. Tur, Tel Aviv Univ. (Israel)

842114 Signal-to-noise ratio improvement in Brillouin optical correlation domain analysis combining Brillovin gain and loss effects [8421-223]

C. Jin, W. Zou, J. Chen, Shanghai Jiao Tong Univ. (China) 
842115 High-spatial-resolution distributed vibration measurement using time-resolved optical frequency-domain reflectometry [8421-300]

D.-P. Zhou, Z. Qin, W. Li, L. Chen, X. Bao, Univ. of Ottawa (Canada)

842116 High-resolution Brillouin fiber sensing using random phase coding of the pump and probe waves [8421-302]

Y. Antman, Bar-llan Univ. (Israel); N. Primerov, L. Thévenaz, École Polytechnique Fédérale de Lausanne (Switzerland); A. Zadok, Bar-llan Univ. (Israel)

842117 100km BOTDA temperature sensor with sub-meter resolution [8421-353]

X. Angulo-Vinuesa, S. Martin-Lopez, P. Corredera, Consejo Superior de Investigaciones

Científicas (Spain); M. Gonzalez-Herraez, Univ. de Alcalá (Spain)

PHYSICAL AND MECHANICAL SENSORS II

842118 Multiphase flow characterization using optical fiber Bragg gratings [8421-539]

V. H. V. Baroncini, C. Martelli, R. L. Patyk, E. N. dos Santos, M. J. da Silva, R. E. M. Morales,

C. E. F. do Amaral, Univ. Tecnológica Federal, Paraná (Brazil)

8421 1A Remote laser-driven solar cell power sources for sensors and devices via kilometer-long optical fibres [8421-271]

J. Canning, L. Vaughan, K. Cook, The Univ. of Sydney (Australia)

8421 1B Distributed birefringence measurement of a polarization maintaining fiber with a $20 \mathrm{~cm}$ resolution over a 500m range based on Brillouin dynamic grating [8421-370]

Y. Dong, Harbin Institute of Technology (China) and Univ. of Ottawa (Canada); H. Zhang, Univ. of Ottawa (Canada) and Harbin Univ. of Science and Technology (China); Z. Lu, Harbin Institute of Technology (China); L. Chen, X. Bao, Univ. of Ottawa (Canada)

8421 1C A fiber-tip Fabry-Perot pressure sensor with graphene diaphragm [8421-422]

J. Ma, W. Jin, H. L. Ho, The Hong Kong Polytechnic Univ. (Hong Kong, China)

MICRO- AND NANO-STRUCTURED FIBER SENSORS II

8421 1D In-fiber integrated optic devices for sensing applications (Invited Paper) [8421-330]

L. Yuan, Harbin Engineering Univ. (China)

$8421 \mathrm{lE}$ Suspended core optical fibers for biological applications using UV wavelengths [8421-235]

S. C. Warren-Smith, The Univ. of Adelaide (Australia); G. Nie, Prince Henry's Institute of Medical Research (Australia); J. Kobelke, Institute of Photonic Technology (Germany); R. Kostecki, The Univ. of Adelaide (Australia); L. A. Salamonsen, Prince Henry's Institute of Medical Research (Australia); T. M. Monro, The Univ. of Adelaide (Australia)

$8421 \mathrm{lF}$ High-sensitivity force measurement using optical tapered fiber with optical frequencydomain reflectometry [8421-403]

X. Wang, W. Li, L. Chen, X. Bao, Univ. of Ottawa (Canada) 
8421 IG Fabrication of a micro-cantilever sensor on a single mode fibre by picoseconds laser [8421-450]

J. Li, F. Albri, R. R. J. Maier, W. N. MacPherson, D. P. Hand, Heriot Watt Univ. (United Kingdom)

$8421 \mathrm{lH} \quad$ Lab on fiber technology: towards multifunctional optical nanosensors [8421-530]

A. Crescitelli, A. Ricciardi, M. Consales, Univ. of Sannio (Italy); E. Esposito, CNR - ICIB (Italy);

A. Cutolo, A. Cusano, Univ. of Sannio (Italy)

\section{SLOW AND FAST LIGHT, AND OTHER EMERGING TECHNOLOGIES}

$842111 \quad$ A brillouin fast light fiber laser sensor (Invited Paper) [8421-598]

O. Kotlicki, Tel Aviv Univ. (Israel); J. Schever, Tel Aviv Univ. (Israel) and Northwestern Univ. (United States); M. S. Shahriar, Northwestern Univ. (United States)

$84211 \mathrm{~J}$ Time/frequency coding for Brillouin distributed sensors [8421-387]

S. Le Floch, F. Sauser, HE-ARC (Switzerland); M. A. Soto, L. Thévenaz, Swiss Federal Institute of Technology (Switzerland)

8421 1K Probing molecular absorption under slow light propagation using a photonic crystal waveguide [8421-389]

I. Dicaire, École Polytechnique Fédérale de Lausanne (Switzerland); A. De Rossi,

S. Combrié, Thales Research and Technology (France); L. Thévenaz, École Polytechnique Fédérale de Lausanne (Switzerland)

8421 1L Spontaneous backscattering in Brillouin dynamic gratings [8421-501]

L. Yaron, Y. Peled, T. Langer, M. Tur, Tel Aviv Univ. (Israel)

\section{SMART STRUCTURES AND SENSOR MULTIPLEXING}

8421 1M A fiber sensor network using fiber optic power supply (Invited Paper) [8421-589]

Y. Tanaka, T. Kurokawa, Tokyo Univ. of Agriculture and Technology (Japan)

8421 iN Wavelength/frequency-division multiplexing of heterodyning fiber grating laser sensors with the assistance of $\mathrm{CO}_{2}$-laser treatment [8421-338]

M. Li, L. Jin, B.-O. Guan, Jinan Univ. (China)

842110 Multichannel fiber optic heterodyne interferometer for the acoustic detection of partial discharges [8421-557]

J. E. Posada, J. A. Garcia-Souto, J. Rubio-Serrano, Univ. Carlos III de Madrid (Spain) 
8421 1P GRIN microendoscopes for high resolution in-vivo fluorescence imaging in small animals (Invited Paper) [8421-212]

J. K. Kim, Harvard Medical School (United States) and Korea Advanced Institute of Science and Technology (Korea, Republic of); S.-H. Yun, Harvard Medical School (United States) and Korea Advanced Institute of Science and Technology (Korea, Republic of) and Harvard-MIT Health Science and Technology (United States)

8421 1Q Demonstration of a flexible, highly sensitive catheter for high resolution manometry based on in-fibre Bragg gratings [8421-171]

C. Bueley, P. Wild, Univ. of Victoria (Canada)

8421 IR A refractive index sensor based on near-surface-core fiber [8421-237]

X. Tian, C. Guan, H. WU, L. Yuan, Harbin Engineering Univ. (China)

8421 is Refractive index sensing measurement based on periodically tapered small core singlemode fibre [8421-252]

P. Wang, Univ. of Southampton (United Kingdom) and Dublin Institute of Technology (Ireland); G. Brambilla, M. Ding, Univ. of Southampton (United Kingdom); L. Bo,

Y. Semenova, Q. WU, G. Farrell, Dublin Institute of Technology (Ireland)

8421 1T Detection of molecular oxygen by magnetic field interaction with guided light within an optical fiber [8421-263]

F. V. Englich, T. M. Monro, The Univ. of Adelaide (Australia)

\section{BIOMEDICAL AND CHEMICAL SENSORS II}

$84211 \mathrm{U}$ Optical coherence elastography: Strain imaging in tissue using optical coherence tomography (Invited Paper) [8421-465]

B. F. Kennedy, K. M. Kennedy, The Univ. of Western Australia (Australia); C. Ford, Curtin Univ. (Australia); R. A. McLaughlin, M. B. Bush, D. D. Sampson, The Univ. of Western Australia (Australia)

$84211 \mathrm{~V}$ High-speed measurement of refractive index using dielectric multilayer films deposited on optical fiber end [8421-287]

K.-S. Kim, Y. Mizuno, K. Nakamura, Tokyo Institute of Technology (Japan)

8421 IW Analysis of fiber-optic probes using graded-index fiber microlenses with non-ideal refractive index profiles [8421-335]

D. Lorenser, X. Yang, D. D. Sampson, The Univ. of Western Australia (Australia)

8421 1X Development of gold nanorod-based localized surface plasmon resonance optical fiber biosensor [8421-446]

J. Cao, City Univ. London (United Kingdom) and Harbin Institute of Technology (China);

T. Sun, K. T. V. Grattan, City Univ. London (United Kingdom) 
8421 IY Microfluidic chip for spectroscopic and refractometric analysis [8421-510]

A. R. Ribeiro, INESC Porto (Portugal) and Univ. do Porto (Portugal); I. Martinho, Univ. Nova de Lisboa (Portugal); J. B. Tillak, INESC Porto (Portugal); I. Bernacka-Wojcik, Univ. do Porto (Portugal); D. Barata, Univ. Nova de Lisboa (Portugal); P. A. S. Jorge, INESC Porto

(Portugal); H. Águas, A. G. Oliva, Univ. Nova de Lisboa (Portugal)

\section{FIBER GRATING SENSORS}

$84211 \mathrm{Z}$ Understanding fiber Bragg gratings at harmonics of the Bragg wavelength through spectra and images (Invited Paper) [8421-310]

S. F. Collins, Victoria Univ. (Australia); S. A. Wade, Swinburne Univ. of Technology (Australia); F. Sidiroglou, G. W. Baxter, Victoria Univ. (Australia)

842120 Nanodiamond coated Bragg gratings for sensing applications [8421-384]

N. J. Alberto, Instituto de Telecomunicações (Portugal) and Univ. of Aveiro (Portugal); J. A. Santos, Univ. of Aveiro (Portugal); C. A. F. Marques, Instituto de Telecomunicações (Portugal); V. F. S. Neto, Univ. of Aveiro (Portugal); R. N. Nogueira, Instituto de Telecomunicações (Portugal)

842121 Hybrid BOTDA/FBG sensor for discrete dynamic and distributed static strain/temperature measurements [8421-205]

T. Nannipieri, M. Taki, F. Zaidi, A. Signorini, Scuola Superiore Sant'Anna (Italy); M. A. Soto, Scuola Superiore Sant'Anna (Italy) and Swiss Federal Institute of Technology (Switzerland); G. Bolognini, Consiglio Nazionale delle Ricerche, IMM Institute (Italy); F. Di Pasquale, Scuola Superiore Sant'Anna (Italy)

842122 Two-dimensional fiber-optic vector vibroscope using only one multi-mode tilted fiber grating [8421-224]

T. Guo, Y. Ran, Y. Tan, S. Gao, L. Sun, B.-O. Guan, Jinan Univ. (China); J. Albert, Carleton Univ. (Canada)

842123 Multiplexed regenerated fiber Bragg gratings for high temperature measurement [8421-240]

G. Laffont, R. Cotillard, P. Ferdinand, Lab. de Mesures Optiques, CEA, LIST (France)

\section{DISTRIBUTED SENSING II}

842124 Double-pulse Brillouin distributed optical fiber sensors: analytical model and experimental validation [8421-368]

M. A. Soto, Swiss Federal Institute of Technology (Switzerland); S. Chin, Omnisens SA

(Switzerland); L. Thévenaz, Swiss Federal Institute of Technology (Switzerland)

842125 Dynamic BOTDA measurements using Brillouin phase-shift [8421-392]

J. Urricelqui, A. Zornoza, M. Sagues, A. Loayssa, Univ. Pública de Navarra (Spain)

842126 High sensitivity optical time-domain reflectometry based on Brillouin dynamic grating in polarization maintaining fiber [8421-400]

K. Y. Song, Chung-Ang Univ. (Korea, Republic of); H. J. Yoon, Korea Railway Research Institute (Korea, Republic of) 
842127 Towards fully distributed amplification and high-performance long-range distributed sensing based on random fiber laser [8421-452]

X.-H. Jia, Univ. Of Electronic Science \& Technology of China (China) and Sichuan Normal Univ. (China); Y.-J. Rao, Z.-N. Wang, W.-L. Zhang, Y. Jiang, J.-M. Zhu, Z.-X. Yang, Univ. of Electronic Science \& Technology of China (China)

842128 Synthesis of optical coherence function to sweep the 0th peak by phase modulation [8421-533]

K. Mori, K. Kajiwara, M. Kishi, Z. He, K. Hotate, The Univ. of Tokyo (Japan)

842129 Interference-fading-free phase-demodulated OTDR system [8421-558]

Z. Pan, K. Liang, J. Zhou, Q. Ye, H. Cai, R. Qu, Shanghai Institute of Optics and Fine Mechanics (China)

\section{SENSOR APPLICATION AND FIELD TESTS}

8421 2A Smart technical textiles based on fibre optic sensors (Invited Paper) [8421-586]

K. Krebber, S. Liehr, J. Witt, Bundesanstalt für Materialforschung und -prüfung (Germany)

$84212 B \quad$ Field test of an in-well fiber laser geophone array [8421-133]

W. Zhang, F. Li, Y. Liu, Institute of Semiconductors (China)

8421 2C Region selectable gas sensing for long distance pipeline maintenance [8421-177] M. Lu, K. Nonaka, H. Kobayashi, Kochi Univ. of Technology (Japan); J. Yang, L. Yuan, Harbin Engineering Univ. (China)

$84212 \mathrm{D}$ Distributed strain and load monitoring of $6 \mathrm{~m}$ composite wing structure by FBG arrays and long-length FBGs [8421-198]

H. Murayama, K. Tachibana, The Univ. of Tokyo (Japan); Y. Hirano, H. Igawa, Japan Aerospace Exploration Agency (Japan); K. Kageyama, K. Uzawa, The Univ. of Tokyo (Japan); T. Nakamura, Japan Aerospace Exploration Agency (Japan)

$84212 \mathrm{E}$ Development of a discriminating fibre optic sensing array for wireless real time analysis of the maritime environment [8421-447]

E. O'Connell, M. Healy, S. O'Keeffe, T. Newe, E. Lewis, Univ. of Limerick (Ireland)

$84212 \mathrm{~F}$ Temperature sensing in a 175MW power generator [8421-541]

C. Martelli, Federal Univ. of Technology, Paraná (Brazil); E. V. da Silva, K. de Morais Souza, Usina Hidrelétrica de Salto Osório (Brazill); F. Mezzadri, Federal Univ. of Technology, Paraná (Brazil); J. Somenzi, M. Crespin, Usina Hidrelétrica de Salto Osório (Brazil); H. J. Kalinowski, Federal Univ. of Technology, Paraná (Brazil); J. Carlos Cordoza da Silva, Usina Hidrelétrica de Salto Osório (Brazil)

$84212 \mathrm{G} \quad$ Hybrid Brillouin-Rayleigh distributed sensing system [8421-560]

K. Kishida, C. H. Li, Neubrex Co. Ltd. (Japan); K. Nishiguchi, Osaka Univ. (Japan);

Y. Yamauchi, A. Guzik, T. Tsuda, Neubrex Co. Ltd. (Japan) 
POSTER SESSION: PHYSICAL, MECHANICAL, ELECTROMAGNETIC, AND FIBER GRATING

$84212 \mathrm{H}$ Development of an optical fiber transducer applied to the measurement of finger movements [8421-13]

E. Fujiwara, Y. T. Wu, M. F. M. Santos, C. K. Suzuki, State Univ. of Campinas (Brazil)

$842121 \quad$ Monitoring drying process of acrylic varnish with heterogeneous optical sensor [8421-15] F. A. M. Saccon, F. M. D. R. de Oliveira, M. Muller, J. L. Fabris, Federal Univ. of Technology, Paraná (Brazil)

$84212 \mathrm{~J}$ Intrinsic, multiplexable sensors for electric field strength using structural slow light in phaseshifted fibre Bragg gratings [8421-3]

P. Orr, P. Niewczas, Univ. of Strathclyde (United Kingdom)

8421 2K Multiplexing tapered optical fibres using coherent optical frequency domain reflectometry [8421-32]

R. Jarzebinska, E. Chehura, S. W. James, R. P. Tatam, Cranfield Univ. (United Kingdom)

8421 2L High pressure discrimination based on optical fiber microsphere cavity Fizeau

interferometer [8421-47]

O. R. Ranjbar, M. I. Zibaii, S. Nouri, Z. Chenari, L. Mehrvar, M. H. Ghezelaiagh, H. Latifi, Shahid Beheshti Univ. (Iran, Islamic Republic of)

$84212 \mathrm{M}$ Design and fabrication of SU-8 MEMS electrostatically funable optical Fabry-Perot cavity based on photolithography technique [8421-55]

L. Mehrvar, S. Nouri, M. Taghavi, F. Beygi Azar, M. Sadegh Cheri, M. I. Zibaii,

M. H. Ghezelaiagh, H. Latifi, Shahid Beheshti Univ. (Iran, Islamic Republic of)

$84212 \mathrm{~N} \quad$ Varifocal imaging using an ultrasonic optical lens with viscoelastic material [8421-57] D. Koyama, Doshisha Univ. (Japan); R. Isago, K. Nakamura, Tokyo Institute of Technology (Japan)

842120 Polarization-dependent bending sensor with temperature insensitivity [8421-67] O.-J. Kwon, H.-J. Kim, Hanyang Univ. (Korea, Republic of); J. Kim, Kyongbuk National Univ. (Korea, Republic of); B. Rho, Korea Photonics Technology Institute (Korea, Republic of); C.-S. Kim, M.-Y. Jeong, Pusan National Univ. (Korea, Republic of); Y.-G. Han, Hanyang Univ. (Korea, Republic of)

$84212 \mathrm{P} \quad$ Compact and high sensitivity curvature sensor based on twin core fiber coupler [8421-86] G. Yin, S. Lou, H. Zou, Beijing Jiaotong Univ. (China)

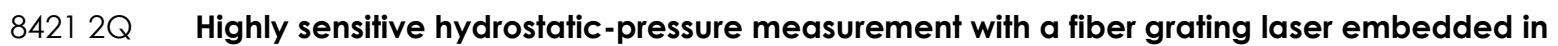
a composite structure [8421-96]

Z. Quan, L. Jin, Y.-L. Chang, B.-O. Guan, Jinan Univ. (China)

$84212 R \quad$ A double-fiber F-P displacement sensor based on direct phase demodulation [8421-136] M. Li, J. Guo, B. Tong, Wuhan Univ. of Technology (China)

$842125 \quad$ A curvature sensor using a novel side-leakage photonic crystal fiber based Sagnac interferometer [8421-142]

S. Lou, X. Sheng, L. Wang, G. Yin, Beijing Jiaotong Univ. (China) 
8421 2T Characterization of longitudinal acoustic waves in a fiber using an extrinsic Fabry-Perot interferometer [8421-157]

R. E. Silva, A. P. Pohl, Federal Univ. of Technology, Paraná (Brazil)

$84212 \mathrm{U}$ Optical electric-field sensor using single $\boldsymbol{\beta}_{-} \mathrm{BaB}_{2} \mathrm{O}_{4}$ crystal [8421-170]

R. Zeng, X. Shen, Tsinghua Univ. (China); C. Li, BeiHang Univ. (China); B. Wang, Tsinghua Univ. (China)

$84212 \mathrm{~V}$ Temperature sensor based on fiber optic pyrometer in material removal processes [8421-184]

A. Tapetado, C. Vázquez, X. Soldani, H. Miguélez, D. S. Montero, Carlos III Univ. of Madrid (Spain)

$84212 \mathrm{~W}$ Simultaneous measurement of partial pressure of $\mathrm{O}_{2}$ and $\mathrm{CO}_{2}$ using hybrid interferometer [8421-220]

P. A. R.. Tafulo, L. Coelho, INESC Porto (Portugal) and Univ. do Porto (Portugal);

P. A. S. Jorge, INESC Porto (Portugal); J. L. Santos, INESC Porto (Portugal) and Univ. do Porto (Portugal); K. Schuster, J. Kobelke, Institute of Photonic Technology (Germany); O. Frazão, INESC Porto (Portugal)

$84212 X \quad$ Interrogation system based on "figure-of-eight" fiber loop mirror [8421-221]

R. M. Silva, INESC Porto (Portugal) and Univ. do Porto (Portugal); A. Layeghi, M. I. Zibaii, H. Latifi, Shahid Beheshti Univ. (Iran, Islamic Republic of); J. L. Santos, INESC Porto (Portugal) and Univ. do Porto (Portugal); A. B. Lobo Ribeiro, Univ. Fernando Pessoa (Portugal); O. Frazão, INESC Porto (Portugal)

$84212 Y \quad$ POF vibration sensor based on speckle pattern changes [8421-241]

L. Rodriguez-Cobo, M. Lomer, C. Galindez, J. M. López-Higuera, Univ. of Cantabria (Spain)

$84212 Z$ Ambient index sensing technique using a Sagnac interferometer incorporating a tapered polarization-maintaining fiber [8421-255]

C.-J. Kang, Y.-G. Han, Hanyang Univ. (Korea, Republic of)

842130 A liquid level sensor based on fiber optic array and magnetic coupling [8421-262] W. He, X. Yu, C. Wang, C. Zhang, B. Feng, M. Yang, Wuhan Univ. of Technology (China)

842131 Multi-monitoring system based on erbium doped fiber ring laser for measurement of radiation dose and strain [8421-304]

Y. B. Shim, H.-J. Kim, Hanyang Univ. (Korea, Republic of); Y. Ji, Korea Institute of Radiological and Medical Science (Korea, Republic of); Y.-G. Han, Hanyang Univ. (Korea, Republic of)

842132 Embedded pressure sensor based on birefringent photonic crystal fiber [8421-311] Y. Yang, X. Zhang, BeiHang Univ. (China); W. Jin, BeiHang Univ. (China) and The Hong Kong Polytechnic Univ. (Hong Kong, China); W. Duan, M. Yang, BeiHang Univ. (China)

842133 Measurement of tunnel-ceiling and side-wall displacements using arc-shaped beam and fiber Bragg grating sensors [8421-319]

H. Naruse, S. Furukawa, T. Nishino, Mie Univ. (Japan) 
842134 Acoustic emission detection using a fiber laser array [8421-336]

W. Zhang, Institute of Semiconductors (China); W. Huang, Institute of Semiconductors

(China) and Shijiazhuang Tiedao Univ. (China); H. Ma, Shijiazhuang Tiedao Univ. (China);

F. Li, Institute of Semiconductors (China)

842135 Fiber optic push-pull accelerometer based on two cantilevers [8421-349]

W. Zhang, F. Li, Institute of Semiconductors (China)

842136 High-sensitivity PCF sensing head for strain measurement [8421-363]

S. Rota-Rodrigo, M. Bravo, A. M. R. Pinto, M. López-Amo, Univ. Pública de Navarra (Spain)

$842137 \quad$ New spatial optical filters for gas refractometry [8421-383]

S. Silva, L. Coelho, R. M. André, INESC Porto (Portugal) and Univ. do Porto (Portugal);

O. Frazão, INESC Porto (Portugal)

842138 Sensitivity characteristics of high-birefringence Sagnac interferometer sensors [8421-401]

P. Zu, C. C. Chan, Z. Liang, Nanyang Technological Univ. (Singapore); Y. Jin, China Jiliang Univ. (China); W. C. Wong, L. H. Chen, Nanyang Technological Univ. (Singapore); X. Dong, China Jiliang Univ. (China)

842139 A weak feedback effect based fiber laser sensor demodulated by a phase generated carrier scheme [8421-411]

J. Zhang, Harbin Engineering Univ. (China) and Univ. of New South Wales (Australia); Z. Yu, Q. Hao, Q. Chai, Q. Li, W. Sun, L. Yuan, Harbin Engineering Univ. (China); G. D. Peng, Univ. of New South Wales (Australia)

$84213 \mathrm{~A}$ Development of a polarimetric vibration sensor for quasi-distributed measurements [8421-431]

N. Linze, P. Tihon, O. Verlinden, P. Mégret, M. Wuilpart, Univ. of Mons (Belgium)

8421 3B Multimode interference in tapered single mode-multimode-single mode fiber structures for strain sensing applications [8421-451]

R. M. André, INESC Porto (Portugal) and Univ. do Porto (Portugal); C. R. Biazoli, Univ. Estadual de Campinas (Brazil); S. O. Silva, M. B. Marques, INESC Porto (Portugal) and Univ. do Porto (Portugal); C. M. B. Cordeiro, Univ. Estadual de Campinas (Brazil); O. Frazão, INESC Porto (Portugal)

$84213 C$ Magnetic field sensor with Terfenol-D thin-film coated FBG [8421-453]

R. M. Silva, INESC Porto (Portugal) and Univ. do Porto (Portugal); G. Chesini, INESC Porto (Portugal) and Univ. Estadual de Campinas (Brazil); C. J. Gouveia, INESC Porto (Portugal) and Univ. da Madeira (Portugal); A. B. Lobo Ribeiro, Univ. Fernando Pessoa (Portugal); O. Frazão, INESC Porto (Portugal); C. M. B. Cordeiro, Univ. Estadual de Campinas (Brazil); P. A. S. Jorge, INESC Porto (Portugal)

$84213 D \quad$ Unbalanced nulling interferometer with four-quadrant phase mask [8421-459] T. Kobayashi, Tokyo Univ. of Agriculture and Technology (Japan) and National Astronomical Observatory of Japan (Japan); J. Nishikawa, National Astronomical Observatory of Japan (Japan); Y. Tanaka, T. Kurokawa, K. Kashiwagi, Tokyo Univ. of Agriculture and Technology (Japan); N. Murakami, N. Baba, Hokkaido Univ. (Japan); N. Hashimoto, Citizen Holdings Co., Ltd. (Japan) 
$84213 \mathrm{E} \quad$ Towed vector fiber optic sensor used in ocean seismic exploration [8421-494]

W. Rao, Y. Hu, Z. Hu, S. Xiong, National Univ. of Defense Technology (China)

$84213 \mathrm{~F}$ Integration of ultralow-noise single-frequency lasers with extrinsic seismic sensors using optical transducers [8421-542]

D. W. Carr, Symphony Sensors, Inc. (United States); Y. Wang, CanaLaser Technologies Co. Ltd. (China)

$84213 G$ Conventional optical fiber current measurements improved by a high accuracy artificial neural network algorithm [8421-547]

A. C. Zimmermann, Univ. Federal de Santa Catarina (Brazill); M. Besen, Univ. do Estado de Santa Catarina (Brazil); L. S. Encinas, Univ. Federal de Santa Catarina (Brazill);

C. M. B. Cordeiro, UNICAMP (Brazil)

$84213 \mathrm{H} \quad$ Optical bidirectional force sensor using optical planar waveguide [8421-561]

M. J. Kim, E. J. Jung, S. H. Hwang, W.-J. Lee, B. S. Rho, Korea Photonics Technology Institute (Korea, Republic of)

$842131 \quad$ Fiber optic bend and temperature sensing in femtosecond laser-structured POF [8421-567] S. Liehr, BAM Federal Institute for Materials Research and Testing (Germany); J. Burgmeier, Fraunhofer Heinrich Hertz Institute (Germany); K. Krebber, BAM Federal Institute for Materials Research and Testing (Germany); W. Schade, Fraunhofer Heinrich Hertz Institute (Germany)

$84213 \mathrm{~J} T$ The characteristics of DFB fiber laser with weak feedback [8421-591]

T. Amine, Y. Zhao, Harbin Engineering Univ. (China); J. Zhang, Harbin Engineering Univ. (China) and The Univ. of New South Wales (Australia); W. Sun, Harbin Engineering Univ.

(China); G. D. Peng, The Univ. of New South Wales (Australia)

$84213 \mathrm{~L}$ Sensitivity analysis and temperature performance of the fiber Bragg grating (FBG) acceleration sensor [8421-9]

J.-Y. Wang, Key Lab. of Optical Fiber Sensoring Technology of Shandong Province (China) and Shandong Academy of Sciences (China); H. Jie, Shandong Micro-Sensor Photonics, Ltd. (China); G.-D. Song, C. Wang, Key Lab. of Optical Fiber Sensoring Technology of Shandong Province (China) and Shandong Academy of Sciences (China); T.-Y. Liu, Key Lab. of Optical Fiber Sensoring Technology of Shandong Province (China) and Shandong Academy of Science (China) and Shandong Micro-Sensor Photonics, Ltd. (China)

$84213 \mathrm{M}$ Toward track component condition monitoring using optical fibre Bragg grating sensors [8421-34]

S. J. Buggy, S. W. James, S. Staines, Cranfield Univ. (United Kingdom); R. Carroll, Stagecoach Supertram (United Kingdom); P. Kitson, D. Farrington, L. Drewett, J. Jaiswal, Tata Steel RD\&T (United Kingdom); R. P. Tatam, Cranfield Univ. (United Kingdom)

$84213 \mathrm{~N}$ Design of a fiber Bragg grating sensor interrogation system using volume phase grating and CCD detection [8421-50]

Z. Cai, J. Hao, B. Dong, J. Phua, T. M. Chiam, Institute for Infocomm Research (Singapore) 
842130 An integrated polarization-holding fiber polarizing grating based on side-polishing and metal film coating techniques [8421-36]

L. Ma, National Univ. of Defense Technology (China) and National and Provincial United Lab. of Fiber Information Engineering Technology (China); N. Jiang, H. Lin, National Univ. of Defense Technology (China); Z. Hu, H. Yang, Y. Hu, National Univ. of Defense Technology (China) and National and Provincial United Lab. of Fiber Information Engineering Technology (China)

$84213 P \quad$ Strain measurement inside a strong pulsed magnet based on embedded fiber Bragg gratings [8421-52]

Q. Zhang, D. Zhang, J. Li, B. Shui, Y. Guo, Wuhan Univ. of Technology (China)

\section{Part 2}

$84213 Q \quad$ Ultrasonic frequency response of surface attached fiber Bragg grating [8421-58]

Z. Li, Virginia Tech (United States) and Beijing Jiaotong Univ. (China); L. Pei, Beijing Jiaotong Univ. (China); B. Dong, C. Ma, A. Wang, Virginia Tech (United States)

8421 3R Optical fiber sensing with chirped FBG Fabry-Perot interferometer: vibration measurement [8421-59]

K. Ikuma, A. Wada, S. Tanaka, National Defense Academy (Japan); K. Omichi, Fujikura Lłd. (Japan); N. Takahashi, National Defense Academy (Japan)

842135 Development of micro-tapered long-period fiber gratings written in tapered fibers with different diameters for enhancement of strain sensitivity [8421-64]

M.-S. Yoon, S.-J. Kim, H.-J. Kim, Y-G. Han, Hanyang Univ. (Korea, Republic of)

8421 3T Enhanced sensitivity of gold modified tapered long period fiber grating for refractive index measurement [8421-70]

Z. Taghipour, M. I. Zibaii, Z. Saeedian, M. H. Ghezelayagh, H. Latifi, Shahid Beheshti Univ. (Iran, Islamic Republic of)

$84213 \mathrm{U} \quad$ Long distance fiber Bragg grating strain sensor interrogation using high speed Ramanbased Fourier domain mode-locked fiber laser with recycled residual Raman pump [8421-79]

S. Kim, O.-J. Kwon, Y.-G. Han, Hanyang Univ. (Korea, Republic of)

$84213 \mathrm{~V}$ Metal packaged fiber Bragg grating accelerometer [8421-87]

Y. Guo, D. Zhang, H. Meng, X. Wen, Z. Zhou, Wuhan Univ. of Technology (China)

8421 3W A miniature fiber Bragg grating pressure sensor for in-vivo sensing applications [8421-99] D. H.-C. Wang, A. Abbott, S. A. Maunder, N. G. Blenman, J. W. Arkwright, CSIRO (Australia)

$84213 X$ Distributed monitoring of fiber Bragg gratings under local lateral loads using optical frequency domain reflectometry [8421-100]

D. Wada, H. Murayama, The Univ. of Tokyo (Japan); H. Igawa, Japan Aerospace Exploration Agency (Japan)

$84213 Y$ Intensity-based LPG vibration sensor array using FBG and broadband optical source [8421-104]

S. Tanaka, A. Wada, K. Ikuma, N. Takahashi, National Defense Academy (Japan) 
$84213 Z$ Tunable narrow-band source using a VCSEL and an EDFA for interrogation of fiber Bragg grating sensors [8421-117]

T. Mizunami, S. Hirose, T. Yoshinaga, K. Yamamoto, Kyushu Institute of Technology (Japan)

842140 Micro-ridge long-period fiber gratings inscribed on a polarization-maintaining fiber for measurement of strain [8421-123]

O.-J. Kwon, M. Shin, Y.-G. Han, Hanyang Univ. (Korea, Republic of)

$842141 \quad$ Optical fibre gratings with response to $2 \mu \mathrm{m}$ and their sensing capabilities [8421-154] A. Adebayo, Z. Yan, L. Zhang, Aston Institute of Photonic Technologies (United Kingdom); D. Robinson, Arden Photonics Ltd. (United Kingdom); P. Li, J. Leng, Harbin Institute of Technology (China)

842142 Detecting mode hopping in fiber ring lasers by anisotropic dynamic gratings [8421-159] P. Xu, National Univ. of Defense Technology (China); Z. Hu, National Univ. of Defense Technology (China) and National and Provincial United Lab of Fiber Information Engineering Technology for Complicated Environment (China); N. Jiang, M. Ma, National Univ. of Defense Technology (China); Y. Hu, National Univ. of Defense Technology (China) and National and Provincial United Lab of Fiber Information Engineering Technology for Complicated Environment (China)

$842143 \quad$ Ultra-long distance fiber Bragg grating sensor system based on self-heterodyne detection [8421-169]

J. Cai, G. Xu, X. Zhao, Nanjing Univ. (China)

842144 The fiber-optic displacement sensor based on the DBR fiber laser [8421-173]

G. Li, Y. Li, K. Yang, M. Liu, Handan College (China)

842145 Comparison between PMMA and PVAC coated fiber Bragg grating sensors for relative humidity measurements [8421-187]

R. Montanini, M. Latino, N. Donato, G. Neri, Univ. of Messina (Italy)

$842146 \quad$ High multiplexing capability and ultrahigh resolution interrogation for optical fiber Bragg grating sensing system [8421-188]

Y. Wang, X. Zhang, Y. Liu, X. Liu, Z. Yang, Beijing Univ. of Posts and Telecommunications (China); Z. Wang, Beijing Jiaotong Univ. (China)

$842147 \quad$ High alternating current sensor based on FBGs and magnetic coupling [8421-189] W. Zhang, C. Zhou, Y. Yao, D. Wang, X. Tong, Wuhan Univ. of Technology (China)

842148 Based on fiber grating the high sensitivity all optical fiber CTD [8421-199] Y.-J. Wang, Institute of Semiconductors (China); X. Dai, Q. Zhao, Institute of Semiconductors (China) and Changchun Univ. of Science and Technology (China); F. Li, Institute of Semiconductors (China); X. Gao, B.-X. Bo, Changchun Univ. of Science and Technology (China)

842149 Remote sensing based on reflective bandpass long-period fiber grating and fiber ring laser [8421-211]

L. Shi, T. Zhu, Q. Zhang, Chongqing Univ. (China); K. S. Chiang, Univ. of Electronic Science and Technology of China (China) and Chongqing Univ. (China) 
8421 4A Enhanced axial strain sensitivity in plasmonic tilted fiber Bragg gratings sensors [8421-218] V. Voisin, C. Caucheteur, P. Mégret, Univ. of Mons (Belgium); J. Albert, Carleton Univ. (Canada)

$84214 \mathrm{~B}$ Simultaneous measurement of refractive index and temperature based on a partial coneshaped FBG [8421-226]

L. Qi, C.-L. Zhao, S. Zhang, Z. Zhang, S. Jin, China Jiliang Univ. (China)

$84214 C$ Fiber-optic thermal anemometer based on metallic coated fiber Bragg grating [8421-229] J. Cheng, Zhejiang Province Institute of Metrology (China); Y. Zhou, Zhejiang Province Institute of Metrology (China) and China Jiliang Univ. (China); X. Dong, China Jiliang Univ. (China); W. Zhou, China Jiliang Univ. (China) and Carleton Univ. (Canada)

8421 4D Dual-peak wide range temperature LPG sensor fabricated with a $\mathrm{CO}_{2}$ Laser and a high resolution system [8421-234]

P. Simões, P. Lopes, Univ. of Aveiro (Portugal)

$84214 \mathrm{E} \quad$ Pipe flow speed sensor based on fiber Bragg gratings [8421-238]

L. Rodriguez-Cobo, M. A. Quintela, M. Lomer, A. Cobo, J. M. López-Higuera, Univ. of Cantabria (Spain)

$84214 \mathrm{~F}$ Determination of chewing patterns in goats using fiber Bragg gratings [8421-275] C. Wosniak, W. J. Silva, R. Cardoso, T. S. Assmann, Federal Univ. of Technology, Paraná (Brazil); J. A. G. Hill, A. L. F. Silveira, Instituto Agronômico do Paraná (Brazil); K. M. Sousa, H. J. Kalinowski, J. C. C. Silva, Federal Univ. of Technology, Paraná (Brazil)

$84214 G$ Dual-polarization DBR fiber laser sensor for liquid-level measurement [8421-281] J. Wo, J. Zhang, Q. Sun, Y. Dai, X. Li, Z. Xu, Huazhong Univ. of Science and Technology (China) and National Engineering Lab. for Next Generation Internet Access System (China); P. P. Shum, Nanyang Technological Univ. (Singapore); D. Liu, Huazhong Univ. of Science and Technology (China) and National Engineering Lab. for Next Generation Internet Access System (China)

$84214 \mathrm{H} \quad$ Novel acoustic emission sensor system based on two cascaded phase-shifted fiber Bragg gratings [8421-288]

Q. WU, Y. Okabe, The Univ. of Tokyo (Japan)

$842141 \quad$ Refractive index sensor employing PVA-coated long period grating technology [8421-299] L. Alwis, K. Bremer, T. Sun, K. T. V. Grattan, City Univ. (United Kingdom)

8421 4J Gap FBG and its application in tunable narrow linewidth fiber laser [8421-314] Y. Yang, X. Zhang, J. Guo, BeiHang Univ. (China); W. Jin, BeiHang Univ. (China) and The Hong Kong Polytechnic Univ. (Hong Kong, China); M. Yang, BeiHang Univ. (China)

$84214 \mathrm{~K}$ Thickness influence on the polarization dependency of tilted fiber Bragg gratings coated by zinc oxide thin films [8421-317] J.-M. Renoirt, C. Zhang, M. Debliquy, M.-G. Olivier, P. Mégret, C. Caucheteur, Univ. of Mons (Belgium) 
$84214 \mathrm{~L}$ Effect of high temperature on the properties of long-period gratings written in nonhydrogenated fibers with UV and electric arc [8421-325]

M. Smietana, Warsaw Univ. of Technology (Poland); W. J. Bock, P. Mikulic, Univ. du Québec en Outaouais (Canada)

$84214 \mathrm{M}$ Performance comparison of fiber Bragg gratings sensor interrogation using two kinds of wavelength-swept lasers [8421-334]

I. G. Park, B. K. Choi, Y. S. Kwon, M. Y. Jeon, Chungnam National Univ. (Korea, Republic of)

$84214 \mathrm{~N} \quad$ Nonlinear response in polymer optical fibre Bragg grating based sensors [8421-354]

W. Zhang, D. J. Webb, Aston Univ. (United Kingdom); G.-D. Peng, Univ. of New South Wales (Australia)

$842140 \quad$ Strain response of POF sensors [8421-361]

A. Abang, D. J. Webb, Aston Univ. (United Kingdom); G.-D. Peng, Univ. of New South Wales (Australia)

$84214 \mathrm{P}$ Temperature level optical fiber sensor using shape memory alloy wires [8421-365] J. M. López-Higuera, L. Rodriguez-Cobo, A. Quintela, R. Hidalgo-Gato, H. Shokry, Univ. of Cantabria (Spain)

$84214 Q \quad$ Ultra-high resolution real-time optical fiber strain sensor using a sideband interrogation method [8421-371]

Q. Liu, T. Tokunaga, Z. He, The Univ. of Tokyo (Japan)

8421 4R Quasidistributed fiber sensor for precast concrete structures monitoring [8421-374] L. Rodriguez-Cobo, J. A. Polanco, A. Quintela, I. A. Carrascal, J. M. López-Higuera, Univ. of Cantabria (Spain)

8421 4S Distributed transverse load sensing with tilted fiber Bragg gratings using optical frequency domain reflectometry [8421-380]

Y. Zhang, Carleton Univ. (Canada); T. Sun, Nanjing Univ. of Information Science \&

Technology (China); L. Xiong, M. Z. Alam, J. Albert, Carleton Univ. (Canada)

8421 4T Temperature compensated microfiber Bragg gratings [8421-386]

S. Gao, L. Jin, Y. Ran, L.-P. Sun, B.-O. Guan, Jinan Univ. (China)

$84214 \mathrm{U}$ Polarization dependency of surface plasmon resonance based tilted fiber Bragg gratings refractometers [8421-396]

C. Caucheteur, V. Voisin, P. Mégret, Univ. of Mons (Belgium); J. Albert, Carleton Univ. (Canada)

$84214 \mathrm{~V}$ Femtosecond laser inscribed phase masks for fibre Bragg grating sensor inscription [8421-407]

G. C. B. Lee, Aston Univ. (United Kingdom); K. Kalli, C. Koutsides, Cyprus Univ. of Technology (Cyprus); Z. Yan, D. Adebayo, Aston Univ. (United Kingdom); M. Komodromos, Frederick Univ. (Cyprus); K. Sugden, Aston Univ. (United Kingdom)

$84214 \mathrm{~W}$ Post-processing techniques for enhancing mode-coupling in long period fiber gratings [8421-414]

Y. Wang, Shenzhen Univ. (China) 
$84214 \mathrm{X} \quad$ Long period grating made by rocking a single mode fiber [8421-416]

W. Jin, H. Xuan, W. Jin, The Hong Kong Polytechnic Univ. (Hong Kong, China)

$84214 \mathrm{Y}$ An investigation of the crack propagation in a carbon-fiber bonded joint using backface strain measurements with FBG sensors [8421-435]

A. Bernasconi, L. Comolli, Politecnico di Milano (Italy)

$84214 Z$ A novel design of a compact S-shaped balance with FBG sensors for the pantographcatenary contact force measurement [8421-438]

M. Bocciolone, L. Comolli, P. Crosio, Politecnico di Milano (Italy)

842150 On the time delays in swept laser FBG interrogators for control systems applications [8421-440]

G. Cazzulani, S. Cinquemani, L. Comolli, Politecnico di Milano (Italy)

842151 Experimental investigation of dynamic characteristics of wavelength of DFB-LD for FBG-FPI vibration sensor based on wavelength-to-time mapping [8421-441]

A. Wada, K. Ikuma, S. Tanaka, N. Takahashi, National Defense Academy (Japan)

842152 Corrosion of Fe-C coated FBG sensor and rebars: a comparative study [8421-454]

W. Hu, X. Chen, H. Cai, M. Yang, W. Chen, Wuhan Univ. of Technology (China)

842153 Highly sensitive type IA fiber Bragg gratings as sensors in radiation environments [8421-464] A. Faustov, SCK CEN (Belgium) and Univ. of Mons (Belgium); P. Saffari, Aston Univ. (United Kingdom); C. Koutsides, Aston Univ. (United Kingdom) and Cyprus Univ. of Technology (Cyprus); A. Gusarov, SCK CEN (Belgium); M. Wuilpart, P. Mégret, Univ. of Mons (Belgium);

L. Zhang, Aston Univ. (United Kingdom); K. Kalli, Cyprus Univ. of Technology (Cyprus)

842154 Refractometer based on a superimposed optical fiber grating [8421-466]

J. Zheng, X. Dong, C. Zhao, S. Jin, China Jiliang Univ. (China)

842155 Bragg gratings in few-mode Er/Al/Bi/P Co-doped germanosilicate ring-core fibre [8421-470]

K. Cook, Univ. of Sydney (Australia); L.-Y. Shao, Univ. of Sydney (Australia) and The Hong Kong Polytechnic Univ. (Hong Kong, China); J. Canning, Univ. of Sydney (Australia); T. Wang, Univ. of Sydney (Australia) and Beijing Jiaotong Univ. (China); Y. Luo, G.-D. Peng, Univ. of New South Wales (Australia)

842156 Acousto-optic modulation in a microstructured plastic optical fibre Bragg grating [8421-472]

L. Bilro, C. A. F. Marques, Instituto de Telecomunicações (Portugal); L. Khan, Aston Institute of Photonic Technologies (United Kingdom); R. A. Oliveira, Volvo 3P-PD Advanced Engineering (Brazil); D. J. Webb, Aston Institute of Photonic Technologies (United Kingdom); R. N. Nogueira, Instituto de Telecomunicações (Portugal)

842157 Fiber optic anemometer based on distributed Bragg reflector fiber laser [8421-481]

Y. Liu, W. Peng, X. Zhang, X. Zhou, Q. YU, Dalian Univ. of Technology (China)

842158 Focal beam position detection in a laser induced breakdown spectroscopy system by using a fiber Bragg grating sensor [8421-485]

F. Anabitarte, L. Rodriguez-Cobo, C. Galindez, A. Ullán, A. Cobo, Univ. of Cantabria (Spain) 
842159 Dynamic temperature compensation interrogation technique for liquid level sensors array based on single-longitudinal-mode DBR fiber laser [8421-498]

C. Jia, B. Liu, H. Zhang, Nankai Univ. (China); Y. Miao, Tianjin Univ. of Technology (China)

8421 5A UV sensor based on azobenzene-polymer-coated FBG [8421-499]

I.-S. Song, C.-Y. Kim, H.-K. Kim, Chosun Univ. (Korea, Republic of); S. N. Lee, Optonest Inc. (Korea, Republic of); T.-J. Ahn, Chosun Univ. (Korea, Republic of)

8421 5B Real-time activity identification in a smart FBG-based fiber-optic perimeter intrusion detection system [8421-511]

H. Wu, X. Lu, S. Li, Y. Wu, Y. Rao, Univ. of Electronic Science and Technology of China (China)

$84215 \mathrm{C}$ Long-distance fiber-optic point-sensing systems based on the second-order random fiber laser [8421-517]

Z. Wang, Y. Rao, H. Wu, P. Li, W. Zhang, Univ. of Electronic Science and Technology of China (China)

$84215 D \quad$ Strain and temperature sensitivity of chiral long period fiber gratings [8421-521]

H.-X. XU, L. Yang, Univ. of Science and Technology of China (China)

$84215 \mathrm{E}$ Thermal characteristics of silver-recoated regenerated grating sensors for hightemperature sensing [8421-525]

Y. Tu, S.-T. Tu, Y.-H. Qi, East China Univ. of Science and Technology (China)

$84215 \mathrm{~F} \quad$ A $1.65 \mu \mathrm{m}$ region external cavity laser diode using an InP gain chip and a fibre Bragg grating [8421-538]

F. Chen, J. Hodgkinson, S. E. Staines, S. W. James, R. P. Tatam, Cranfield Univ. (United Kingdom)

$84215 \mathrm{G}$ Intensity-independent fiber coupled interrogation technique for fiber Bragg gratings by fiber Bragg gratings [8421-540]

J. Burgmeier, J. Koch, W. Schade, Fraunhofer-Institut für Nachrichtentechnik Heinrich-HertzInstitut (Germany) and Technische Univ. Clausthal (Germany)

$84215 \mathrm{H} \quad$ Designing sensing properties of the long-period fiber gratings coated with the LC layers [8421-573]

A. Czapla, W. J. Bock, Univ. du Québec en Outaouais (Canada); T. R. Woliński, Warsaw Univ. of Technology (Poland)

842151 Study and application of CFBG vibration sensor with symmetrical push-pull configuration [8421-45]

Q. Nan, Wuhan Univ. of Technology (China)

8421 5J A PGC demodulation based on differential-cross-multiplying (DCM) and arctangent (ATAN) algorithm with low harmonic distortion and high stability [8421-355]

X. Yang, Z. Chen, J. H. Ng, Institute for Infocomm Research (Singapore); V. Pallayil,

U. K. C., National Univ. of Singapore (Singapore) 
POSTER SESSION: BIOMEDICAL AND CHEMICAL SENSOR, MICRO-STRUCTURED FIBER SENSORS, SENSOR MULTIPLEXING

$84215 \mathrm{~K}$ Study of antibacterial effect of nanosilver particle by tapered optical fiber sensor [8421-22] Z. Saeedian, M. I. Zibaii, S. M. Hosseini, H. Latifi, Shahid Beheshti Univ. (Iran, Islamic Republic of)

$84215 \mathrm{~L} \quad$ Label free detection of quadruplex formation of peroxidase-like DNAzyme by tapered fiber optic biosensor [8421-69]

Z. Bagheri, Tarbiat Modares Univ. (Iran, Islamic Republic of) and Shahid Beheshti Univ. (Iran, Islamic Republic of); Z. Chenari, Shahid Beheshti Univ. (Iran, Islamic Republic of); Z. Karami, Tarbiat Modares Univ. (Iran, Islamic Republic of); M. I. Zibaii, Shahid Beheshti Univ. (Iran, Islamic Republic of); B. Ranjbar, Tarbiat Modares Univ. (Iran, Islamic Republic of); H. Latifi, Shahid Beheshti Univ. (Iran, Islamic Republic of)

$84215 \mathrm{M}$ DNA detection using molecular beacon in soft-glass microstructured optical fibers [8421-95]

L. V. Nguyen, S. C. Warren-Smith, A. Cooper, T. M. Monro, The Univ. of Adelaide (Australia)

$84215 \mathrm{~N}$ Optical coherence tomography for endoscopes, using imaging fibre bundles and a conical mirror [8421-293]

H. D. Ford, R. P. Tatam, Cranfield Univ. (United Kingdom)

842150 Instantaneous spectroscopic SS-OCT imaging using a simultaneous dual-band swept laser and common-path fiber probe [8421-301]

Y. Mao, S. Chang, C. Flueraru, E. Murdock, National Research Council Canada (Canada)

$84215 \mathrm{P}$ Temperature compensation fiber-optic refractive index sensor based on single-mode fiber core-offset attenuator [8421-309]

H. Cheng, Z. Jing, P. Wei, C. Xing, Dalian Univ. of Technology (China)

$84215 Q \quad$ Label-free DNA biosensor based on cladding-etched thin-core fiber modal interferometer [8421-381]

G. Ma, A. P. Zhang, G. Yan, Y. Bai, Zhejiang Univ. (China) and Joint Research Lab. of Optics of Zhejiang Normal Univ. and Zhejiang Univ. (China); Y. Hu, Zhejiang Univ. (China) and Zhejiang Univ. of Technology (China); X. Ye, Zhejiang Univ. (China)

$84215 R \quad$ A novel biosensor based on a coupled surface plasmon nanostructure [8421-390] Y. Ma, G. Farrell, Y. Semenova, Dublin Institute of Technology (Ireland); H. P. Chan, City Univ. of Hong Kong (Hong Kong, China); Q. Wu, Dublin Institute of Technology (Ireland)

842155 Dual-band wavelength-swept active mode locking laser for multi-band fiber-optic sensors [8421-421]

H. D. Lee, C. S. Kim, M. Y. Jeong, Pusan National Univ. (Korea, Republic of); Z. Chen, Pusan National Univ. (Korea, Republic of) and Univ. of California, Irvine (United States)

$84215 T$ Dispersion-tuned wavelength-swept fiber laser using a chirped FBG and a reflective SOA for OCT applications [8421-426]

Y. Takubo, S. Yamashita, The Univ. of Tokyo (Japan) 
$84215 \mathrm{U}$ Fabrication and characterization of fiber-optic dosimeters for diagnostic radiology usages [8421-479]

W. J. Yoo, S. H. Shin, K.-T. Han, D. Jeon, J.-Y. Park, Konkuk Univ. (Korea, Republic of);

B. G. Park, Soonchunhyang Univ. (Korea, Republic of); B. Lee, Konkuk Univ. (Korea,

Republic of)

$84215 \mathrm{~V} \quad$ A label-free antigen-antibody immunosensor based on a special double cladding fiber [8421-520]

W. Cao, F. Pang, N. Chen, Z. Chen, T. Wang, Shanghai Univ. (China)

$84215 \mathrm{~W}$ Strain monitoring of the periodontal ligament in pig's mandibles [8421-527]

L. Z. Karam, Federal Univ. of Technology, Paraná (Brazil); M. S. Milczewski, Federal Univ. of Technology, Paraná (Brazil) and Brazilian Dentistry Association (Brazil); H. J. Kalinowski,

Federal Univ. of Technology, Paraná (Brazil)

$84215 X \quad$ Sensing biodiesel and biodiesel-petrodiesel blends [8421-5]

M. S. Kawano, T. K. M. Cardoso, G. R. C. Possetti, R. C. Kamikawachi, J. L. Fabris, M. Muller, Federal Univ. of Technology, Paraná (Brazil)

$84215 Y \quad$ Structure optimization of slotted photonic crystal waveguide for gas sensor [8421-44]

Y. Zhao, Y.-N. Zhang, D. Wu, Q. Wang, Northeastern Univ. (China)

$84215 Z$ Effect of the clad transparency condition in POF humidity sensors with the swelling polymer clad [8421-71]

S. Kato, M. Morisawa, Univ. of Yamanashi (Japan)

842160 Study of ring-down signal processing for fiber-loop ring-down sensing technology [8421-114]

D. Fan, Wuhan Univ. of Technology (China) and Virginia Tech (United States); J. Gong,

A. Wang, Virginia Tech (United States)

842161 An optical fibre salinity sensor based on fluorescence quenching mechanism [8421-158]

T. H. Nguyen, City Univ. London (United Kingdom); Y. Zhao, Northeastern Univ. (China);

T. Sun, K. T. V. Grattan, City Univ. London (United Kingdom)

842162 Comparison of side-polished fiber Bragg grating hydrogen sensors sputtered with Pd/Ag and $\mathrm{Pd} / \mathrm{Y}$ composite films [8421-164]

J. Dai, M. Yang, Z. Yang, Wuhan Univ. of Technology (China); X. Yu, Huazhong Univ. of Science and Technology (China); K. Cao, J. Liao, P. Zhang, Science and Technology on Surface Physics and Chemistry Lab. (China)

842163 Long period grating inscribed by femtosecond laser for refractive index measurements in aqueous environments [8421-180]

L. B. Melo, F. Ahmed, M. Jun, P. Wild, Univ. of Victoria (Canada)

842164 Real-time monitoring of fermentation process applied to sugarcane bioethanol production [8421-228]

E. Fujiwara, E. Ono, The State Univ. of Campinas (Brazil); C. K. Yamakawa, J. L. lenczak, C. E. V. Rossell, Brazilian Bioethanol Science and Technology Lab. (Brazil); C. K. Suzuki, The State Univ. of Campinas (Brazil) 
842165 A fiber-optic methane gas sensor system with improved accuracy using absorptionspectrum matched comb filter [8421-236]

D. Liu, M. Tang, Z. Zhao, S. Fu, D. Liu, P. Shum, Huazhong Univ. of Science and Technology

(China) and Wuhan National Lab. for Optoelectronics (China)

842166 Enhanced RI sensor using a combination of a long period fiber grating and a small core singlemode fiber (SCSMF) structure [8421-251]

Q. Wu, Y. Ma, Y. Semenova, P. Wang, Dublin Institute of Technology (Ireland); H. P. Chan, City Univ. of Hong Kong (Hong Kong, China); G. Farrell, Dublin Institute of Technology (Ireland)

842167 Numerical modeling and performance optimization of QEPAS spectrophone [8421-266]

Y. Cao, W. Jin, H. L. Ho, The Hong Kong Polytechnic Univ. (Hong Kong, China)

842168 Coating based fiber Bragg grating humidity sensor array [8421-269]

L.-K. Cheng, A. Boersma, R. Jansen, TNO (Netherlands)

842169 Using optical fiber sidewall to capture light from an adjustable depth [8421-326]

J. Ma, Y. Chiniforooshan, W. J. Bock, Univ. du Québec en Outaouais (Canada)

84216 A Fiber optic pH sensor with self-assembled multilayer nanocoatings on tilted FBG [8421-329] L. Y. Shao, China Jiliang Univ. (China) and The Hong Kong Polytechnic Univ. (Hong Kong, China); M. J. Yin, H. Y. Tam, The Hong Kong Polytechnic Univ. (Hong Kong, China); J. Albert, Carleton Univ. (Canada)

$84216 \mathrm{~B} \quad \mathrm{SnO}_{2}$ based optical fiber refractometers [8421-393]

P. Sánchez, C. R. Zamarreño, M. Hernaez, I. Del Villar, I. R. Matias, F. J. Arregui, Public Univ. of Navarra (Spain)

$84216 \mathrm{C}$ Miniature photonic crystal optical fiber humidity sensor based on polyvinyl alcohol [8421-409]

W. C. Wong, C. C. Chan, Nanyang Technological Univ. (Singapore); T. Li, China Jiliang Univ. (China); L. H. Chen, J. Boo, K. X. Lee, Nanyang Technological Univ. (Singapore);

K. C. Leong, GLOBALFOUNDRIES Singapore Pte Ltd. (Singapore)

8421 6D High finesse interferometric hydrogen sensor based on fiber-optic Fabry-Perot cavity modulations [8421-418]

Y. H. Kim, C. Lee, J. H. Kwon, Y.-T. Lee, B. H. Lee, Gwangju Institute of Science and Technology (Korea, Republic of)

$84216 \mathrm{E}$ An evaluation of the distribution of metal ions in otherwise uniform titania sol-gel layers designed for optical sensing using laser ablation inductive coupled plasma mass spectroscopy [8421-420]

G. Huyang, J. Canning, Univ. of Sydney (Australia); D. Bishop, A. McDonagh, Univ. of Technology (Australia); M. J. Crossley, Univ. of Sydney (Australia)

$84216 \mathrm{~F}$ Highly sensitive temperature-independent refractive index sensor based on compact highly birefringent microfiber loop [8421-424]

L. Sun, J. Li, Y. Tan, X. Shen, X. Xie, S. Gao, B.-O. Guan, Jinan Univ. (China) 
$84216 G$ Suppression of long distance instability on remote sensing signal of pulse correlation measurement in optical fiber sensing [8421-425]

H. Kobayashi, T. Tsuzuki, T. Onishi, Y. Masaoka, Kochi Univ. of Technology (Japan); X. Xu, Key Lab. of State Grid Corp. of China (China); K. Nonaka, Kochi Univ. of Technology (Japan)

$84216 \mathrm{H}$ Tunable diode laser spectroscopy with electronically controlled background RAM nulling [8421-467]

A. Upadhyay, V. V. Katre, A. L. Chakraborty, Indian Institute of Technology Gandhinagar (India)

842161 Increased sensitivity of long period grating hydrogen sensors through coupling to higher order cladding modes [8421-489]

R. M. Carter, R. R. J. Maier, Heriot-Watt Univ. (United Kingdom); P. Biswas, S.

Bandyopadhyay, N. Basumallick, Central Glass and Ceramics Research Institute (India); B. J. S. Jones, S. McCulloch, Atomic Weapons Establishment (United Kingdom); J. S. Barton, Heriot-Watt Univ. (United Kingdom)

$84216 \mathrm{~J}$ Chemical vapor sensing properties of twin-core photonic crystal fiber based in-reflection interferometer [8421-507]

B. Kim, K. Naeem, J. Han, Y. Chung, Gwangju Institute of Science and Technology (Korea, Republic of)

8421 6K Fiber carbon monoxide sensing system and its application in coal mines [8421-519] Y. Wei, T. Zhang, Y. Li, Y. Zhao, T. Liu, C. Wang, Shandong Academy of Sciences (China)

$84216 \mathrm{~L} \quad$ LPG based fiber optic sensor for carbon dioxide [8421-532]

C. Gouveia, INESC Porto (Portugal) and Univ. da Madeira (Portugal); K. Balogh, INESC Porto (Portugal) and Univ. of Pécs (Hungary); J. M. Baptista, INESC Porto (Portugal) and Univ. da Madeira (Portugal); B. Kovacs, Univ. of Pécs (Hungary); P. A. S. Jorge, INESC Porto (Portugal)

$84216 \mathrm{M}$ Simultaneous measurement of refractive index and temperature based on multimode interference inside a fiber loop mirror [8421-534]

C. Gouveia, INESC Porto (Portugal) and Univ. da Madeira (Portugal); G. Chesini, Univ. Estadual de Campinas (Brazil); J. M. Baptista, INESC Porto (Portugal) and Univ. da Madeira (Portugal); C. M. B. Cordeiro, Univ. Estadual de Campinas (Brazil); P. A. S. Jorge, INESC Porto (Portugal)

$84216 \mathrm{~N}$ SERS properties of gold core silver shell nanoparticles self-assembled on silica substrates and optical fiber endface [8421-554]

Q. Geng, Z. Chen, N. Chen, S. Liu, C. Qian, T. Wang, Shanghai Univ. (China)

842160 Temperature independent refractive index measurement using white light interferometry [8421-555]

C. Gouveia, INESC Porto (Portugal) and Univ. da Madeira (Portugal); M. Zibaii, H. Latifi, Shahid Beheshti Univ. (Iran, Islamic Republic of); M. J. Marques, INESC Porto (Portugal) and FCUP (Portugal); J. M. Baptista, INESC Porto (Portugal) and Univ. da Madeira (Portugal);

P. A. S. Jorge, INESC Porto (Portugal)

$84216 \mathrm{P}$ Enhanced novel fiber-optic sensor for efficient fluorescence collection [8421-569]

Y. Chiniforooshan, J. Ma, W. J. Bock, Univ. du Québec en Outaouais (Canada) 
$84216 Q \quad$ Temperature independent microbending polarization maintaining photonic-crystal-fiber based microdisplacement sensor [8421-16]

B. Dong, J. Hao, Institute for Infocomm Research (Singapore)

$84216 R \quad$ Liquid-core photonic crystal fiber based surface plasmon resonance refractive index sensor [8421-72]

B. Shuai, L. Xia, D. Liu, Huazhong Univ. of Science and Technology (China)

842165 Temperature threshold sensor based on optical switch with filled photonic crystal fiber [8421-74]

P. Marc, P. Piliszek, Military Univ. of Technology (Poland); M. Murawski, M. Szymanski, T. Nasilowski, Military Univ. of Technology (Poland) and InPhoTech Ltd. (Poland); K. Pawlik, InPhoTech Ltd. (Poland); L. R. Jaroszewicz, Military Univ. of Technology (Poland)

$84216 \mathrm{~T} \quad H o l l o w-c o r e ~ p h o t o n i c ~ b a n d g a p$ fiber Mach-Zehnder interferometer based on a long period grating and an offset-splice joint [8421-78]

X. YU, Heilongjiang Univ. (China); J. Ju, W. Jin, The Hong Kong Polytechnic Univ. (Hong Kong, China); J. Zhang, S. Liu, Heilongjiang Univ. (China)

$84216 \mathrm{U}$ An inline ultrasensitive temperature sensor based on liquid-filled photonic crystal fiber Mach-Zehnder modal interferometer [8421-85]

Y. Geng, X. Li, Shenzhen Univ. (China); X. Tan, Ningbo Univ. (China); Y. Deng, Y. Yu, Shenzhen Univ. (China)

$84216 \mathrm{~V}$ Sensitivity enhancement in photonic crystal fiber interferometer [8421-129]

S. Qiu, Y. Chen, Nanjing Univ. (China)

$84216 \mathrm{~W}$ Simultaneous measurement of strain and temperature based on clover microstructured fiber loop mirror [8421-131]

R. A. Perez-Herrera, Univ. Pública de Navarra (Spain); R. M. André, S. F. Silva, INESC Porto (Portugal); M. Becker, K. Schuster, J. Kobelke, Institute of Photonic Technology (Germany); M. López-Amo, Univ. Pública de Navarra (Spain); J. L. Santos, O. Frazão, INESC Porto (Portugal)

$84216 \mathrm{X} \quad$ Hollow core photonic crystal fiber as a viscosity sensor [8421-140]

L. E. Horan, F. C. Garcia Gunning, Univ. College Cork (Ireland)

$84216 \mathrm{Y}$ Chromatic dispersion measurement in photonic crystal fiber by white-light interferometry [8421-141]

G. Ran, J. Yi, Beijing Institute of Technology (China)

$84216 Z$ Pressure-assisted low-loss fusion splicing between photonic crystal fibers and single-mode fiber [8421-214]

F. Xiao, T. Zhu, L. Xu, M. Deng, Chongqing Univ. (China)

$842170 \quad$ Hydrostatic pressure sensor using two-core photonic crystal fiber [8421-216]

Z. Liu, M.-L. V. Tse, The Hong Kong Polytechnic Univ. (Hong Kong, China); D. Chen, Zhejiang Normal Univ. (China); C. LU, H.-Y. Tam, The Hong Kong Polytechnic Univ. (Hong Kong, China) 
842171 Photonic crystal fiber-based silver-nanowires LSPR sensors with supermodes [8421-332] C. Zhou, Beijing Jiaotong Univ. (China) and Univ. of Jinan (China); J. Yao, Tianjin Univ. (China)

842172 Hybrid square-lattice photonic crystal fiber with high birefringence and negative dispersion [8421-345]

S. E. Kim, Gwangju Institute of Science and Technology (Korea, Republic of); C. G. Lee, I. Moon, Chosun Univ. (Korea, Republic of); C.-S. Kee, Gwangju Institute of Science and Technology (Korea, Republic of)

842173 Optical fiber sensors fabricated by the focused ion beam technique [8421-351]

W. Yuan, Singapore Institute of Manufacturing Technology (Singapore); F. Wang, Technical Univ. of Denmark (Denmark); O. Bang, Techincal Univ. of Denmark (Denmark)

842174 Surface plasmon resonance sensor based on a novel grapefruit photonic crystal fiber [8421-408]

P. Zhang, J. Yao, L. Jing, H. Cui, Y. Lu, Tianjin Univ. (China)

842175 Microstructured polymer optical fiber-based surface plasmon resonance sensor [8421-410] Y. Lu, B. Wu, X. Fu, C. Hao, X. Huang, J. Yao, Tianjin Univ. (China)

842176 Overcoupled bending insensitive holey optical fiber coupler [8421-428] J. B. Eom, I. H. Shin, J. S. Park, B. I. Lee, Korea Photonics Technology Institute (Korea, Republic of)

842177 A high sensitivity humidity sensor based on an Agarose coated photonic crystal fiber interferometer [8421-442]

J. Mathew, Y. Semenova, G. Farrell, Dublin Institute of Technology (Ireland)

842178 Comparison of vibration measurements in composite materials using different types of polarimetric sensors [8421-445]

M. Ramakrishnan, Dublin Institute of Technology (Ireland); G. Rajan, The Univ. of New South Wales (Australia); Y. Semenova, Dublin Institute of Technology (Ireland); T. Woliński, Warsaw Univ. of Technology (Poland); G. Farrell, Dublin Institute of Technology (Ireland)

842179 Inline Mach-Zehnder interferometer using liquid filled twin-core photonic crystal fiber with high strain sensitivity. [8421-456]

K. Naeem, B. Kim, J. Han, Y. Chung, Gwangju Institute of Science and Technology (Korea, Republic of)

$84217 \mathrm{~A}$ Brillouin scattering of a photonic crystal fiber core-offset spliced to a single mode fiber [8421-457]

Y. Chang, H. Liang, J. Li, L. Cheng, B.-O. Guan, Jinan Univ. (China)

8421 7B A Mach-Zehnder interferometer by combining a microtaper with a long period grating in an all solid photonic bandgap fiber and its temperature sensing characteristic [8421-469] Z. Wu, Nankai Univ. (China) and Nanyang Technological Univ. (Singapore); M. Jiang, Nanyang Technological Univ. (Singapore) and CINTRA CNRS/NTU/THALES (Singapore); Y. Liu, Z. Wang, Nankai Univ. (China); P. P. Shum, Nanyang Technological Univ. (Singapore) and CINTRA CNRS/NTU/THALES (Singapore); X. Q. Dinh, CINTRA CNRS/NTU/THALES (Singapore) and Thales Solutions Asia Pte Ltd. (Singapore) 
$84217 \mathrm{C}$ Surface plasmon resonance sensor based on grapefruit fiber filled with silver nanowires [8421-471]

C. Hao, Y. Lu, X. Fu, J. Yao, Tianjin Univ. (China)

8421 7D Temperature and strain response of Michelson interferometer with asymmetric two-core photonic crystal fiber [8421-473]

J. Han, B. Kim, K. Naeem, Y. Chung, Gwangju Institute of Science and Technology (Korea, Republic of)

$84217 E$ Strain and temperature sensitivity measurement using simple microstructured fiber MachZhender interferometer [8421-531]

M. Murawski, M. Szymanski, Military Univ. of Technology (Poland) and InPhoTech Ltd. (Poland); Z. Holdynski, Military Univ. of Technology (Poland); T. Tenderenda, L. Ostrowski, Military Univ. of Technology (Poland) and InPhoTech Ltd. (Poland); K. Pawlik, InPhoTech Ltd. (Poland); A. Lukowski, Military Univ. of Technology (Poland); H. Krisch, Krohne Messtechnik GmbH (Germany); P. Marć, L. R. Jaroszewicz, Military Univ. of Technology (Poland); T. Nasilowski, Military Univ. of Technology (Poland) and InPhoTech Ltd. (Poland)

$84217 F \quad$ Dispersion properties of double-clad hollow-core photonic bandgap fibers based on a circular lattice cladding [8421-535]

H. Stawska, E. Bereś-Pawlik, Wrocław Univ. of Technology (Poland)

$84217 G \quad$ Birefringence responses of hybrid photonic crystal fiber to strain and temperature [8421-544]

M. Pang, The Hong Kong Polytechnic Univ. (Hong Kong, China); L. M. Xiao, Univ. of Bath (United Kingdom); W. Jin, The Hong Kong Polytechnic Univ. (Hong Kong, China); A. C. S. Jr., National Institute of Telecommunications (Brazil)

$84217 \mathrm{H} \quad$ Photonic crystal fibers as miniature monitoring platforms for petroleum characterization [8421-548]

R. L. Patyk, C. Martelli, M. J. da Silva, R. E. M. Morales, Univ. Tecnológica Federal do Paraná (Brazil); M. Naqshbandi, J. Canning, The Univ. of Sydney (Australia)

842171 Surface plasmon resonance sensor based on a novel grapefruit photonic crystal fiber [8421-579]

P. Zhang, J. Yao, L. Jing, H. Cui, Y. Lu, Tianjin Univ. (China)

$84217 \mathrm{~J}$ Selectively infiltrated photonic crystal fibers for strain measurement with ultra-high sensitivity [8421-4]

Y. Wang, The Hong Kong Polytechnic Univ. (Hong Kong, China) and Wuhan Institute of Technology (China); D. N. Wang, The Hong Kong Polytechnic Univ. (Hong Kong, China)

$84217 \mathrm{~K}$ Thinned fiber based Mach-Zehnder interferometer for measurements of liquid level and refractive index [8421-14]

L. Li, L. Xia, Z. Xie, D. Liu, Huazhong Univ. of Science and Technology (China)

$84217 \mathrm{~L} \quad$ Multiplexed localized surface plasmon resonance sensing with suspended core fibers [8421-42]

K. Schröder, M. Zobel, A. Csáki, A. Schwuchow, W. Fritzsche, R. Willsch, H. Bartelt, Institute of Photonic Technology (Germany) 
$84217 \mathrm{M}$ Principle of the temperature sensor based on two mode nano-wire Silicon-on-Insulator waveguides [8421-49]

Z. Wang, L. Zhang, J. Wang, Beijing Jiaotong Univ. (China)

$84217 \mathrm{~N}$ In-line single-mode fiber interferometers based on peanut-shape fiber structure [8421-77] D. Wu, T. Zhu, D.-W. Duan, Chongqing Univ. (China); K. S. Chiang, City Univ. of Hong Kong (Hong Kong, China) and Chongqing Univ. (China); M. Deng, Chongqing Univ. (China)

842170 Sensing characteristics of tapered high-birefringent optical fiber [8421-127] A. Layeghi, M. I. Zibaii, Shahid Beheshti Univ. (Iran, Islamic Republic of) and INESC Porto (Portugal); J. Sadeghi, Shahid Beheshti Univ. (Iran, Islamic Republic of); O. Frazão, P. A. S. Jorge, INESC Porto (Portugal); H. Latifi, Shahid Beheshti Univ. (Iran, Islamic Republic of)

$84217 P$ A fast-response microfiber coupler tip high temperature sensor [8421-150] M. Ding, Univ. of Southampton (United Kingdom); P. Wang, Univ. of Southampton (United Kingdom) and Dublin Institute of Technology (Ireland); G. Brambilla, Univ. of Southampton (United Kingdom)

$84217 Q \quad$ Spectral bandwidth analysis of high sensitivity refractive index sensor based on multimode interference fiber device [8421-160]

E. G. P. Pachon, IFGW, UNICAMP (Brazil); M. A. R. Franco, Instituto de Estudos Avançados (Brazil) and Instituto Tecnologico de Aeronautica (Brazil); C. M. B. Cordeiro, IFGW, UNICAMP (Brazil)

$84217 R$ Optical fiber hydrogen sensor based on micro interferometer [8421-175]

M. Wang, J. Cheng, Wuhan Univ. of Technology (China); X. YU, Huazhong Univ. of Science \& Technology (China); J. Dai, G. Zhang, M. Yang, Wuhan Univ. of Technology (China)

\section{Part 3}

842175 FBG-microfiber-FBG cascade Fabry-Perot interferometer for simultaneous measurement of temperature and refractive index [8421-217]

J. Zhang, Q. Sun, R. Liang, J. Wo, D. Liu, National Engineering Lab. for Next Generation Internet Access System (China) and Huazhong Univ. of Science and Technology (China)

$84217 \mathrm{~T}$ Temperature sensor by using alcohol-filled side-hole fiber based Sagnac interferometer [8421-227]

Y. Xin, X. Dong, Q. Meng, F. Qi, C. Zhao, Y. Jin, S. Jin, China Jiliang Univ. (China)

$84217 \mathrm{U}$ High sensitivity temperature sensor using microfiber based Mach-Zehnder interferometer [8421-277]

R. Liang, Q. Sun, J. Wo, J. Zhang, W. Jia, D. Liu, Huazhong Univ. of Science and Technology (China)

$84217 \mathrm{~V}$ Temperature-independent refractive index sensor based on a Bragg grating in highly birefringent microfiber [8421-279]

Y. Ran, L. Jin, L.-P. Sun, J. Li, B.-O. Guan, Jinan Univ. (China) 
8421 7W In-fiber microsphere air-cavity Fabry-Perot interferometer for strain/temperature measurement [8421-321]

J. Ma, W. Jin, The Hong Kong Polytechnic Univ. (Hong Kong, China)

$84217 X \quad$ Fiber Bragg gratings in few-mode highly birefringent microstructured optical fibers for sensing applications [8421-356]

T. Tenderenda, M. Murawski, M. Szymanski, Military Univ. of Technology (Poland) and InPhoTech Ltd. (Poland); M. Becker, M. Rothhardt, H. Bartelt, Institute of Photonic Technology (Germany); P. Mergo, Maria Curie-Sklodowska Univ. (Poland); K. Poturaj, InPhoTech Ltd. (Poland) and Maria Curie-Sklodowska Univ. (Poland); M. Makara, Maria Curie-Sklodowska Univ. (Poland); K. Skorupski, InPhoTech Ltd. (Poland) and Maria CurieSklodowska Univ. (Poland); P. Marc, L. R. Jaroszewicz, Military Univ. of Technology (Poland); T. Nasilowski, Military Univ. of Technology (Poland) and InPhoTech Ltd. (Poland)

$84217 Y \quad$ An investigation of the polarization dependence of a temperature sensor based on an optical microfiber coupler [8421-391]

L. Bo, Dublin Institute of Technology (Ireland); P. Wang, Dublin Institute of Technology (Ireland) and Univ. of Southampton (United Kingdom); Y. Semenova, Dublin Institute of Technology (Ireland); G. Brambilla, Univ. of Southampton (United Kingdom); G. Farrell, Dublin Institute of Technology (Ireland)

842172 Monitoring of fluid evaporation using fiber-optic micro-cells [8421-397]

E. Preter, Bar-llan Univ. (Israel); B. Preložnik, Univ. of Maribor (Slovenia); C. N. Sukenik, Barllan Univ. (Israel); D. Donlagic, Univ. of Maribor (Slovenia); A. Zadok, Bar-llan Univ. (Israel)

842180 Fiber taper sensors fabrication with arbitrary profiles using a modified flame-brush approach [8421-412]

A. Felipe, G. Espíndola, Y. Wang, L. H. Negri, Santa Catarina State Univ. (Brazil); H. J. Kalinowski, Federal Univ. of Technology, Paraná (Brazil); A. S. Paterno, Santa Catarina State Univ. (Brazil)

842181 Raman detection of hydrogen peroxide in suspended core optical fibers [8421-423] G. Tsiminis, The Univ. of Adelaide (Australia); N. A. Spooner, The Univ. of Adelaide (Australia) and Defence Science and Technology Organisation (Australia); T. M. Monro, The Univ. of Adelaide (Australia)

842182 Controlling the fabrication of self-assembled microwires from silica nanoparticles [8421-429]

M. Naqshbandi, J. Canning, M. Nash, M. J. Crossley, The Univ. of Sydney (Australia)

842183 In-line fluidic absorption coefficient sensor based on optical microfiber [8421-448] Z. Wei, Z. Song, X. Zhang, Z. Meng, National Univ. of Defense Technology (China)

842184 Spectral tuning of a microfiber coupler with a liquid crystal overlay [8421-482] Y. Semenova, L. Bo, S. Mathews, Dublin Institute of Technology (Ireland); P. Wang, Dublin Institute of Technology (Ireland) and Univ. of Southampton (United Kingdom); Q. Wu, G. Farrell, Dublin Institute of Technology (Ireland)

842185 A high-speed and high-precision phase-shift demodulation algorithm for optical fiber sensing system based on low-coherence interference [8421-486]

S. Wang, J. Jiang, T. Liu, K. Liu, J. Yin, X. Meng, S. Wang, Z. Qin, Y. Zhang, Tianjin Univ. (China) 
842186 A highly sensitive and fast response molecular sensor based on graphene coated microfiber [8421-513]

B. Yao, Y. Wu, Y. Gong, Y. Rao, Univ. of Electronic Science and Technology of China (China)

842187 Laser-machined cascaded micro cavities for simultaneous measurement of dual parameters [8421-515]

Z. Ran, C. Li, M. Ni, E. Lu, Y. Rao, Univ. of Electronic Science and Technology of China (China)

842188 Lab on fiber using self-assembly technique: a preliminary study [8421-522]

M. Pisco, G. Quero, Univ. degli Studi del Sannio (Italy); A. Iadicicco, Univ. degli Studi di Napoli Parthenope (Italy); M. Giordano, National Research Council (Italy); F. Galeotti, Consiglio Nazionale delle Ricerche (Italy); A. Cusano, Univ. degli Studi del Sannio (Italy)

842189 Sensing properties of intrinsic Fabry-Perot interferometers in fiber tapers [8421-545] X. Zhang, J. Li, Y. Li, W. Wang, F. Pang, Y. Liu, T. Wang, Shanghai Univ. (China)

8421 8A Noise analysis and optimization for PGC method [8421-81]

Z. Dai, C. Tian, Tsinghua Univ. (China); K. Wang, Tianjin Univ. (China); L. Wang, M. Zhang, Y. Liao, Tsinghua Univ. (China)

$84218 B \quad$ Interrogation of remote intensity-based fiber-optic sensors deploying delay lines in the virtual domain [8421-126]

D. S. Montero, C. Vázquez, Univ. Carlos III de Madrid (Spain)

$84218 \mathrm{C}$ Resilient optical fiber ladder network with OADMs to multiplex sensors: experimental validation of binary state connectivity analysis [8421-134]

R. A. Perez-Herrera, D. Leandro, P. Urquhart, Univ. Pública de Navarra (Spain); M. Schlüter, Hochschule Niederrhein (Germany); M. Lopez-Amo, Univ. Pública de Navarra (Spain)

$84218 D \quad$ Investigation on the scale of DFB fiber laser sensor array limited by coherence collapse [8421-194]

W. Liu, L. Ma, H. Yang, National Univ. of Defense Technology (China)

$84218 \mathrm{E} \quad$ BOTDA sensor network with power by light remote switching [8421-233]

A. Ullán, Univ. de Cantabria (Spain); M. Bravo, A. Zornoza, A. Loayssa, M. Lopez-Amo, Univ. Pública de Navarra (Spain); J. M. López-Higuera, Univ. de Cantabria (Spain)

$84218 F \quad$ Remote resilient FBG multiplexing network controlled by a powered by light fiber optic switch [8421-250]

M. Bravo, M. A. Erro, J. M. Algueta, S. Diaz, M. Lopez-Amo, Univ. Pública de Navarra (Spain)

$84218 \mathrm{G}$ Interferometric time division FBG interrogator and multiplexer with static, dynamic, and absolute wavelength measurement capabilities [8421-295]

P. Orr, A. Paterson, P. Niewczas, Univ. of Strathclyde (United Kingdom) 
$84218 \mathrm{H} \quad$ High performance fibre-optic acoustic sensor array using a distributed EDFA and hybrid TDM/DWDM, scalable to 4096 sensors [8421-327]

Y. Liao, Univ. of Southampton (United Kingdom); E. Austin, P. J. Nash, S. A. Kingsley, Stingray Geophysical Ltd. (United Kingdom); D. J. Richardson, Univ. of Southampton (United Kingdom)

$842181 \quad$ Range-resolved single-sideband optical fibre interferometry for quasi-distributed dynamic strain sensing [8421-352]

T. Kissinger, T. O. H. Charrett, R. P. Tatam, Cranfield Univ. (United Kingdom)

8421 8J 200-km long fiber ring laser for multiplexing fiber Bragg gratings arrays [8421-359] M. Fernandez-Vallejo, M. Bravo, M. Lopez-Amo, Univ. Pública de Navarra (Spain)

$84218 \mathrm{~K}$ Wavelength division multiplexing technique for grating panel-based fiber optic sensor [8421-437]

Y.-G. Lee, KAIST (Korea, Republic of); D.-H. Kim, Seoul National Univ. of Science and Technology (Korea, Republic of); J.-H. Kim, Y.-Y. Kim, C.-G. Kim, KAIST (Korea, Republic of)

$84218 \mathrm{~L}$ Dynamical strain sensing via discrete reflectors interrogated by optical frequency domain reflectometry [8421-462]

O. Y. Sagiv, D. Arbel, Y. Katz, Y. Grotas, A. Eyal, Tel Aviv Univ. (Israel)

POSTER SESSION: FIBER OPTIC GYROSCOPES, NEW FIBERS AND COATING MATERIALS, DISTRIBUTED SENSING, SENSOR APPLICATION AND OTHER EMERGING TECHNOLOGIES

$84218 \mathrm{M} \quad H y b r i d$ linear and circular polarization Er-doped fiber ring laser gyroscopes [8421-168]

K. Li, J. Su, L. Yang, J.-R. Qian, Univ. of Science and Technology of China (China)

$84218 \mathrm{~N}$ Design in depolarized FOGs using effective model and genetic algorithm [8421-182] Y.-L. Lo, C.-C. Yen, Y.-F. Chung, H.-H. Lin, National Cheng Kung Univ. (Taiwan); R.-Y. Liu, National Space Organization (Taiwan)

$842180 \quad$ Radiation resistant fibers with depressed claddings for fiber optic gyro sensing coil [8421-260]

A. M. Kurbatov, R. A. Kurbatov, Kuznetsov Research Institute for Applied Mechanics (Russian Federation)

$84218 P \quad$ Frequency noise characteristics of a narrow-linewidth DFB semiconductor laser in resonator fiber optic gyro [8421-488]

G. Zhang, H. Ma, Z. Jin, Zhejiang Univ. (China)

$84218 Q \quad$ Advanced techniques for evaluating the quality of fiber gyro coils [8421-490] Z. Meng, Tianjin Univ. (China) and Suzhou Optoring Technology Co. Ltd. (China); X. S. Yao, Tianjin Univ. (China) and General Phontonics Corp. (United States); Z. Li, Tianjin Univ. (China) and Suzhou Optoring Technology Co. Ltd. (China); Z. Ding, L. Wang, J. Can, Tianjin Univ. (China); J. Xu, Suzhou Optoring Technology Co. Ltd. (China); T. Liu, Tianjin Univ. (China)

8421 8R Optimization of frequency stabilization loop for resonator fiber optic gyro [8421-493] X. YU, H. Ma, Z. Jin, Zhejiang Univ. (China) 
842185 Dependences of Brillouin frequency shift on strain and temperature in optical fibers doped with rare-earth ions [8421-38]

Y. Mizuno, N. Hayashi, K. Nakamura, Tokyo Institute of Technology (Japan)

$84218 \mathrm{~T}$ Polarization-maintaining fiber with wide temperature resistance [8421-90] Y. Endoh, K. Hayashi, K. Izoe, K. Aikawa, M. Kudoh, R. Yamauchi, Fujikura Ltd. (Japan)

$84218 \mathrm{U}$ Development of a sensitive fiber optic sensor monitoring NO based on vicinal diaminobenzoacridine fluorophore [8421-92]

L. Ding, C. Fan, J. Huang, Wuhan Univ. of Technology (China); B. Liang, F. Yuan, Second Affiliated Hospital of GuangZhou Medical Univ. (China); D. Gong, Yangzhou Optoelectrical Products Testing Institute (China)

$84218 \mathrm{~V} \quad$ Brillouin frequency shift dependences on temperature and strain in PMMA-based polymer optical fibers estimated by acoustic velocity measurement [8421-192]

N. Hayashi, Y. Mizuno, D. Koyama, K. Nakamura, Tokyo Institute of Technology (Japan)

$84218 \mathrm{~W}$ Theoretical and experimental analysis of the birefringence in embedded-core hollow optical fibers [8421-242]

C. Guan, X. Tian, D. Gao, F. Tian, J. Shi, L. Yuan, Harbin Engineering Univ. (China)

$84218 X \quad$ Fabrication of coaxial dual-waveguide structured optical fiber with an annular waveguide layer [8421-257]

T. Zhang, G. Y. Liu, Z. C. Fan, X. Li, Q. Dai, J. Yang, L. B. Yuan, Harbin Engineering Univ. (China)

$84218 Y$ Design of a novel quasi-Airy beam generator: Airy optical fiber [8421-331]

H. Deng, L. Yuan, Harbin Engineering Univ. (China)

$84218 Z$ A wavelength division multiplexer based on a cocentric core fiber [8421-333]

E. Zhao, T. Zheng, A. Zhou, L. Yuan, Harbin Engineering Univ. (China)

842190 An integration strain sensor based on symmetrical twin-core fiber [8421-433]

G. Li, A. Zhou, Q. Xu, T. Zheng, L. Yuan, Harbin Engineering Univ. (China)

842191 Input-polarization-induced phase noise in interferometric fiber-optic sensors and its reduction using polarization diversity receivers [8421-48]

H. Lin, National Univ. of Defense Technology (China); L. Ma, Y. Hu, National Univ. of Defense Technology (China) and National and Provincial United Lab of Fiber Information Engineering Technology (China)

842192 Photonic generation of microwave signal using a dual-wavelength fiber ring laser with CMFBG filter and saturable absorber [8421-75]

S. Feng, W. Peng, Q. Li, C. Qi, T. Feng, S. Jian, Beijing Jiaotong Univ. (China)

842193 Superstructured FBG based optical encoder/decoder for highly-confidential 40 Gbps telecommunication network [8421-111]

K. Omichi, R. Nomura, Fujikura Ltd. (Japan); R. Matsumoto, Osaka Univ. (Japan); S. Shimizu, National Institute of Information and Communications Technology (Japan); Y. Terada, A. Sakamoto, R. Yamauchi, Fujikura Ltd. (Japan); N. Wada, National Institute of Information and Communications Technology (Japan); K. Kitayama, Osaka Univ. (Japan) 
842194 Dual-m-phase-shift distributed fiber laser for strain sensing [8421-208]

X. Zhang, Laser Institute of Shandong Academy of Science (China); G. Peng, Univ. of New South Wales (Australia); C. Wang, Z. Sun, Z. Song, J. Ni, Laser Institute of Shandong Academy of Science (China)

842195 Noise floor analysis of the phase demodulation scheme using a $3 \times 3$ coupler [8421-264] H. Zhang, Tsinghua Univ. (China) and National Ocean Technology Ctr. (China); M. Zhang, Y. Liao, Tsinghua Univ. (China)

842196 Light power sensor by using a photosensitive liquid crystal hybrid film on side polished fiber [8421-339]

J. Yu, H. Li, Jinan Univ. (China); V. K. Hsiao, National Chi Nan Univ. (Taiwan); W. Liu, J. Tang, Y. Zhai, Y. Du, J. Zhang, Y. Xiao, Z. Chen, Jinan Univ. (China)

842197 Wide range group delay tuning in lossy fiber ring resonators [8421-362]

$X$. Angulo-Vinuesa, Consejo Superior de Investigaciones Cientificas (Spain); M. Bravo, Univ. Pública de Navarra (Spain); S. Martin-Lopez, Consejo Superior de Investigaciones Cientificas (Spain); M. Lopez-Amo, Univ. Pública de Navarra (Spain); M. Gonzalez-Herraez, Univ. de Alcalá (Spain)

842198 Individual or simultaneous temperature and strain monitoring by high birefringence fiber loop mirror with reduced cross sensitivity [8421-430]

G. Sun, S. Li, Shantou Univ. (China); Y. Chung, Gwangju Institute of Science and Technology (Korea, Republic of)

842199 Integral temperature hybrid laser sensor [8421-461]

C. A. Galindez, L. Rodriguez-Cobo, F. Anabitarte, J. M. López-Higuera, Univ. de Cantabria (Spain)

8421 9A Distributed pressure measurement by Brillouin scattering dynamic grating for a two side holes fiber [8421-18]

S. Nouri Jouybari, H. Latifi, Z. Chenari, Shahid Beheshti Univ. (Iran, Islamic Republic of)

8421 9B Optical fiber properties influence on strain coefficient $C_{\varepsilon}$ of Brillouin frequency shift [8421-31]

Y. S. Mamdem, EDF R\&D (France); F. Taillade, IFSTTAR (France); Y. Jaouën, R. Gabet, Telecom ParisTech (France); G. Moreau, EDF R\&D (France); X. Phéron, S. Delepine-Lesoille, ANDRA (France)

$84219 C$ Distributed fiber optic pressure sensors based on a photonic crystal fiber [8421-35] W. Ding, Y. Jiang, Beijing Institute of Technology (China)

$84219 D \quad$ Study on multi-channel distributed fiber optic gas monitoring system [8421-39] Z. Li, Y. Xie, Wuhan Univ. of Technology (China)

8421 9E Improvement of pulse shape on Brillovin optical time domain reflectometry [8421-54] Y. Hao, Shanghai Institute of Optics and Fine Mechanics (China) and Zhengzhou Univ. of Light Industry (China); Q. Ye, Z. Pan, H. Cai, R. Qu, Shanghai Institute of Optics and Fine Mechanics (China) 
8421 9F Single-ended distributed Brillouin sensing with high spatial resolution [8421-62] Z. Yang, X. Hong, J. Wu, H. Guo, J. Lin, Beijing Univ. of Posts and Telecommunications (China)

$84219 G \quad$ Brillouin optical time domain reflectometry using a reference Brillouin ring laser [8421-107] X. Zhang, R. Wang, Y. Yao, Nanjing Univ. (China)

$84219 \mathrm{H}$ Spatial resolution improvement based on intensity modulation in measurement of Brillouin dynamic grating localized by correlation domain technique [8421-118]

R. K. Yamashita, Z. He, K. Hotate, The Univ. of Tokyo (Japan)

842191 Verification of Brillouin optical correlation domain reflectometry by numerical simulation [8421-119]

S. Manotham, M. Kishi, Z. He, K. Hotate, The Univ. of Tokyo (Japan)

$84219 \mathrm{~J}$ The use of Walsh functions in modulating pump light of high-spatial-resolution BOTDA with NRZ pulses [8421-130]

M. S. D. B. Zan, T. Tsumuraya, T. Horiguchi, Shibaura Institute of Technology (Japan)

$84219 \mathrm{~K}$ Birefringence distribution mapping in optical fibers with a coherent polarization-OTDR [8421-135]

S. Yang, X. Wei, C. Gao, Beijing Glass Research Institute (China); C. Wu, Beijing Jiaotong Univ. (China); Y. Wang, Beijing Univ. of Posts and Telecommunications (China)

$84219 \mathrm{~L}$ Photonic doppler velocimetry system based on bare fiber probe [8421-165]

J. Wang, C. Bi, H. Xiang, C. Wu, Beijing Jiaotong Univ. (China)

$84219 \mathrm{M}$ Raman-assisted DPP-BOTDA sensor employing Simplex coding with sub-meter scale spatial resolution over 93-km standard SMF [8421-203]

M. Taki, Scuola Superiore Sant'Anna (Italy); M. A. Soto, Scuola Superiore Sant'Anna (Italy) and Swiss Federal Institute of Technology (Switzerland); G. Bolognini, IMM Institute (Italy);

F. Di Pasquale, Scuola Superiore Sant'Anna (Italy)

$84219 \mathrm{~N}$ Simultaneous multi-point measurement of refractive index using optical fiber sensor based on an arrayed-waveguide grating [8421-270]

J.-H. Li, C.-L. Zhao, C.-K. Ji, China Jiliang Univ. (China)

842190 Mechanism of refractive index distribution measurement based on etched fiber Bragg grating [8421-278]

B. Luo, Chongqing Univ. of Technology (China) and Univ. of Electronic Science and Technology of China (China); M. Zhao, Chongqing Univ. of Technology (China); X. Zhou, S. Shi, Univ. of Electronic Science and Technology of China (China); X. Han, Y. Wang, Chongqing Univ. of Technology (China)

8421 9P Distributed optical fiber vibration waveform sensing system based on compensating interferometer [8421-282]

J. Wang, S. Xiong, X. Liang, Q. Yao, J. Zhu, Y. Hu, National Univ. of Defense Technology (China) 
$84219 Q \quad H y d r o g e n$ influence on Brillouin and Rayleigh distributed temperature or strain sensors [8421-292]

S. Delepine-Lesoille, J. Bertrand, ANDRA (France); L. Lablonde, iXFiber (France); X. Phéron, ANDRA (France)

$84219 R \quad$ Time division multiplexing optical time domain reflectometry by directly synthesizing heterodyne intermediate frequency [8421-312]

X. Zhang, Y. Song, L. Lu, F. Zhu, Nanjing Univ. (China)

$842195 \quad$ Investigation on threshold of stimulated Raman scattering in optical fibers [8421-313] Y. Yang, T. Jiang, BeiHang Univ. (China); W. Jin, BeiHang Univ. (China) and The Hong Kong Polytechnic Univ. (Hong Kong, China); M. Yang, BeiHang Univ. (China)

$84219 \mathrm{~T}$ Brillouin gain spectrum characteristics for temperature compensation in fiber optic distributed strain sensor [8421-322]

A. Wosniok, BAM Federal Institute for Materials Research and Testing (Germany)

$84219 \mathrm{U}$ Reflection properties of Brillouin dynamic gratings in coiled single-mode fibers [8421-328] S. Takigawa, T. Horiguchi, Shibaura Institute of Technology (Japan)

$84219 \mathrm{~V} \quad$ Ultra-sensitivity, ultra-large dynamic all-fiber optical coherence domain polarimetry [8421-350]

J. Yang, Harbin Engineering Univ. (China) and Ministry of Education (China); Y. Yuan, J. Chai, B. Wu, F. Peng, Ministry of Education (China); A. Zhou, Z. Liu, L. Yuan, Harbin Engineering Univ. (China) and Ministry of Education (China)

$84219 \mathrm{~W} \quad$ High performance phase demodulator for interferometric optical fiber sensor using novel ameliorated PGC algorithm [8421-364]

G. Wang, T. Xu, F. Li, Institute of Semiconductors (China)

$84219 X \quad$ Brillouin sensing for perimetric detection: the SmartFence project [8421-366]

P. Ferdinand, S. Rougeault, N. Roussel, Lab. de Mesures Optiques, LIST, CEA (France);

M. Pinabiau, Lab. de Protection Physique, SPACl, CEA (France); C. Canepa,

J.-C. Da Rocha, A. Poulain, ACOME (France); R. Blin, S. Piot, SITES S. A. (France); L. Gourit,

D. Brunet, C. Finck, RTE Akustik+Prüftechnik GmbH (France)

$84219 Y \quad$ Bipolar pulse coding for enhanced performance in Brillouin distributed optical fiber sensors [8421-373]

M. A. Soto, Swiss Federal Institute of Technology (Switzerland); S. Le Floch, HE-ARC (Switzerland); L. Thévenaz, Swiss Federal Institute of Technology (Switzerland)

$84219 Z$ Impacts of Kerr effect and fiber dispersion on long-range Brillouin optical time-domain analysis systems [8421-378]

Y. Dong, Harbin Institute of Technology (China) and Univ. of Ottawa (Canada); H. Zhang, Univ. of Ottawa (Canada) and Harbin Univ. of Science and Technology (China); Z. Lu, Harbin Institute of Technology (China); L. Chen, X. Bao, Univ. Of Ottawa (Canada)

$8421 \mathrm{AO}$ Continuous wavelet transform for non-stationary vibration detection with phase-OTDR [8421-395]

Z. Qin, L. Chen, X. Bao, Univ. of Ottawa (Canada) 
8421 Al Sweep-free Brillouin time-domain analysis (SF-BOTDA) with improved spatial resolution [8421-398]

A. Voskoboinik, A. E. Willner, Univ. of Southern California (United States); M. Tur, Tel Aviv Univ. (Israel)

8421 A2 Performance tests of PM optical fiber coupler based on optical coherence domain polarimetry [8421-443]

W. Bing, J. Yang, Y. Yuan, H. Lv, C. Liu, A. Zhou, L. Yuan, Harbin Engineering Univ. (China) and Ministry of Education (China)

8421 A3 Research on coherent Rayleigh backscattering and signal processing method in phaseOTDR [8421-477]

X. Chen, X. Zhang, B. Yan, Anhui Institute of Optics and Fine Mechanics (China); J. Li, Heriot-Watt Univ. (United Kingdom); X. Chen, G. Tu, Y. Liang, Z. Ni, Anhui Institute of Optics and Fine Mechanics (China); B. Culshaw, Univ. of Strathclyde (United Kingdom); F. Dong, Anhui Institute of Optics and Fine Mechanics (China)

8421 A4 Brillouin scattering based sensor in high gamma dose environment: design and optimization of optical fiber for long-term distributed measurement [8421-492] $X$. Phéron, ANDRA (France) and Lab. Hubert Curien, CNRS (France); J. Bertrand, ANDRA (France); S. Girard, CEA, DAM, DIF (France); Y. Ouerdane, Lab. Hubert Curien, CNRS (France); S. Delepine-Lesoille, ANDRA (France); A. Boukenter, Lab. Hubert Curien, CNRS (France)

8421 A5 Life-cycle monitoring for RC structural prestress loss utilizing optical fiber distributed sensors [8421-508]

C. Lan, Harbin Institute of Technology (China); Z. Zhou, Dalian Univ. of Technology (China); J. Ou, Harbin Institute of Technology (China) and Dalian Univ. of Technology (China)

8421 A6 A hybrid Raman/FBG sensing system for simultaneous measurement of temperature and strain [8421-514]

F. Peng, Z. Ran, Y. Rao, Y. Liu, Univ. of Electronic Science and Technology of China (China)

8421 A7 Rating the performance of a Brillouin distributed fiber sensor [8421-536]

L. Thévenaz, M. A. Soto, École Polytechnique Fédérale de Lausanne (Switzerland)

8421 A8 Reducing location error and processing time of dual Mach-Zehnder interferometric fiber perturbation sensor using zero-crossing analysis [8421-549]

X. Zhang, T. Liu, K. Liu, J. Jiang, Z. Ding, Q. Chen, Tianjin Univ. (China)

8421 A9 Continuous online partial discharge monitoring system [8421-19]

Z. Chen, Institute for Infocomm Research (Singapore); K. T. Ng, Hoestar PD Technology Pte Ltd. (Singapore); J. H. Ng, Institute for Infocomm Research (Singapore); J. Y. K. Koh, Hoestar PD Technology Pte Ltd. (Singapore); J. T. Teo, S. H, Ng, T. S. P. See, Institute for Infocomm Research (Singapore); W. H. Leong, Hoestar PD Technology Pte Ltd. (Singapore)

8421 AA Desensitized encapsulation FBG sensor for smart cable in bridge [8421-20] S. Li, D. Jiang, Wuhan Univ. of Technology (China); X. Zhao, Jiangsu Fasten Group Co. (China)

$8421 A B \quad$ Carbon-coated fiber Fabry-Perot sensor for harsh environments [8421-28]

X. Zhou, W. Peng, Q. YU, Dalian Univ. of Technology (China) 
8421 AC On-line load monitoring of a tufting needle using optical fibre Bragg grating sensors [8421-33]

E. Chehura, G. Dell'Anno, T. Huet, S. Staines, S. W. James, I. Partridge, R. P. Tatam, Cranfield Univ. (United Kingdom)

8421 AD Mechanical strength of silica fiber splices after exposure to extreme temperatures [8421-41]

M. Perry, P. Niewczas, Univ. of Strathclyde (United Kingdom); M. Johnston, EDF Energy

Nuclear Generation Ltd. (United Kingdom); K. Cook, J. Canning, Univ. of Sydney (Australia)

8421 AE A new-type non-contact FBG vibration detecting sensor for rotating machinery [8421-82] G. Xu, Y. Dai, X. Niu, Q. Nan, Wuhan Univ. of Technology (China)

8421 AF High-accuracy optical pressure sensor for gas turbine monitoring [8421-89]

F. F. M. Maillaud, R. D. Pechstedt, Oxsensis Ltd. (United Kingdom)

8421 AG An optical fiber F-P acoustic emission sensor system for the detection of steel crack initiation [8421-102]

X. Tong, T. Ji, Wuhan Univ. of Technology (China); W. Wei, Zhejiang Univ. (China); C. Wen, X. Zhu, Z. Leng, Wuhan Univ. of Technology (China)

$8421 \mathrm{AH}$ Model analysis of single-mode optical fiber extrinsic Fabry-Perot interferometric sensors [8421-105]

W. Wang, M. Zhang, Q. Tan, Tsinghua Univ. (China)

8421 Al Pipeline auto-mapping system based on inertial technology [8421-113]

S. Gao, X. Li, T. Lin, BeiHang Univ. (China)

8421 AJ Phase noise characteristics for four-wave transmission in a long-haul interferometric fiber sensing system [8421-120]

W. Chen, Z. Meng, H. Zhou, National Univ. of Defense Technology (China)

8421 AK Depolarizer improvement for optical fiber vibration sensor [8421-122]

T. Kubo, A. Takahashi, Fujikura Ltd. (Japan); N. Zhao, Fujikura China Co., Ltd. (China);

R. Yamauchi, Fujikura Ltd. (Japan)

$8421 \mathrm{AL}$ Research of laser induced breakdown spectroscopy for detection of trace Cd in polluted soil [8421-124]

S. Chen, X. Ma, H. Zhao, H. Lv, Tsinghua Univ. (China)

8421 AM Condition monitoring of reciprocating compressor using FBG-based sensors in petrochemical industry [8421-128]

Y. Dai, G. XU, X. Niu, Q. Nan, M. Yang, Wuhan Univ. of Technology (China)

8421 AN A common path fibre optic based interferometric displacement sensor with enhanced range [8421-132]

D. A. Jackson, R. Cernat, A. Podoleanu, Univ. of Kent (United Kingdom)

$8421 \mathrm{AO} \quad$ Rail corrugation measurement using fiber laser accelerometers [8421-137]

W. Huang, Institute of Semiconductors (China) and Shijiazhuang Tiedao Univ. (China);

Y. Du, Shijiazhuang Tiedao Univ. (China); W. Zhang, Institute of Semiconductors (China);

H. Ma, Shijiazhuang Tiedao Univ. (China); F. Li, Institute of Semiconductors (China)

xxxviii 
8421 AP Effect of temperature on methane gas concentration by tunable diode laser absorption spectroscopy [8421-143]

Y. Zhao, Y. Wei, Y. Li, T. Zhang, C. Wang, T. Liu, Laser Institute of Shandong Academy of Sciences (China)

$8421 \mathrm{AQ}$ The rail bridge bearing monitoring system base on FBG [8421-147]

J. Liu, X. Miao, Y. Yuan, Hubei Polytechnic Univ. (China)

8421 AR A hetero-core spliced fiber optic SPR sensor network for extensive-area natural environment monitoring [8421-148]

L. S. Goh, K. Watanabe, N. Shinomiya, Soka Univ. (Japan)

8421 AS Diffuse-light absorption spectroscopy for discriminating Belgian beers [8421-151]

A. G. Mignani, L. Ciaccheri, A. A. Mencaglia, CNR - Istituto di Fisica Applicata (Italy);

E. E. Samano-Baca, H. Ottevaere, H. Thienpont, Vrije Univ. Brussel (Belgium)

8421 AT Experimental qualification and validation of fibre optic strain sensors [8421-153]

C. Schilder, N. Kusche, V. G. Schukar, W. R. Habel, BAM Federal Institute for Materials Research and Testing (Germany)

$8421 \mathrm{AU}$ Displacement monitor with FBG deforming ring and its application in high speed railway [8421-172]

W. Li, Y. Zhang, Q. Wang, J. Pan, J. Liu, C. Zhou, Wuhan Univ. of Technology (China)

8421 AV The bridge heavy vehicle identification system based on optical fiber sensing technology [8421-176]

L. Yue, Wuhan Univ. of Technology (China)

8421 AW Structural health monitoring of reinforced concrete beams by means of embedded fiber Bragg grating sensors [8421-191]

R. Montanini, F. De Domenico, F. Freni, N. Maugeri, A. Recupero, Univ. degli Studi di Messina (Italy)

$8421 \mathrm{AX} \quad$ Field test of an eight-element fiber laser hydrophone array [8421-201]

W. Zhang, F. Li, Y. Liu, Institute of Semiconductors (China)

8421 AY Optical fiber sensing technology application in long span highway-railway cable-stayed bridge [8421-207]

Y. Yang, Wuhan Univ. of Technology (China)

8421 AZ Continuous pressure and temperature monitoring in fast rotating paper machine rolls using optical FBG sensor technology [8421-209]

W. Ecke, Institute of Photonic Technology (Germany); M. W. Schmitt, Voith Paper Fabrics GmbH \& Co. KG (Germany); Y. Shieh, Voith Paper Fabrics and Rolls Inc. (United States); E. Lindner, FBGS Technologies (Germany); R. Willsch, Institute of Photonic Technology (Germany)

8421 B0 A four-element optical fiber 4C vector hydrophone array [8421-210] J. Wang, H. Luo, Y. Chen, Z. Meng, National Univ. of Defense Technology (China) 
8421 B 1 Smart material using fiber Bragg grating transducers and shape memory alloy actuators [8421-239]

L. Rodriguez-Cobo, A. Quintela, A. Cobo, J. M. López-Higuera, Univ. of Cantabria (Spain)

8421 B2 Floating OE sensor array for offshore marine oil spill monitoring and pollution control [8421-254]

H. L. Cui, D. Li, T. Koscica, D. C. Song, J. L. Zou, L. C. Gao, L.C. Pegasus Corp. (United States)

8421 B3 Validation of an induction motor thermal model by using fiber Bragg grating temperature sensors [8421-274]

K. de Morais Sousa, H. J. Kalinowski, J. Carlos Cardozo da Silva, Federal Univ. of

Technology, Paraná (Brazil)

8421 B4 Phase locked loop based topography measurement of ultraprecision machined surface using the ball lensed and tapered fiber [8421-303]

C. Lee, Gwangju Institue of Science and Technology (Korea, Republic of); J.-H. Kang, Univ. School of Oriental Medicine (Korea, Republic of); J.-Y. Joo, Korea Photonics Technology Institute (Korea, Republic of); S.-K. Lee, Gwangju Institue of Science and Technology

(Korea, Republic of)

8421 B5 Earthquake monitoring using fiber laser borehole seismometer [8421-306]

W. Zhang, Institute of Semiconductors (China); W. Huang, Shijiazhuang Tiedao Univ. (China) and Institute of Semiconductors (China); F. Li, Institute of Semiconductors (China)

8421 B6 The influence of parameters measurement error on demodulation performance of PGC arctangent algorithm in optical fiber hydrophone [8421-315]

K. Wang, Tianjin Univ. (China); Q. Shi, Tsinghua Univ. (China) and Beijing Institute of Aerospace Systems Engineering (China); Z. Dai, C. Tian, S. Xie, Tsinghua Univ. (China);

C. Yang, Tianjin Univ. (China); S. Cao, Tsinghua Univ. (China); F. Duan, Tianjin Univ. (China);

M. Zhang, Y. Liao, Tsinghua Univ. (China)

8421 B7 Test and calibration of Bragg grating based vibration sensors [8421-316]

S. Andresen, T. R. Licht, F. K. Nielsen, Brüel \& Kjaer Sound \& Vibration Measurement A/S (Denmark)

8421 B8 Web-based refractive index monitoring system, employing LPG-FBG hybrid optical sensors [8421-337]

O. Koyama, T. Kanamori, K. Kawanishi, Y. Katsuyama, Osaka Prefecture Univ. (Japan)

8421 B9 All fibre-optic simultaneous detection of optical and acoustic emission from partial discharges in silicone elastomer [8421-357]

P. Rohwetter, BAM Federal Institute for Materials Research and Testing (Germany); T. Kielau, Beuth Hochschule für Technik Berlin (Germany); C. Lothongkam, BAM Federal Institute for Materials Research and Testing (Germany); G. Heidmann, IPH GmbH (Germany); W. Habel, BAM Federal Institute for Materials Research and Testing (Germany)

8421 BA Field calibration device for Raman backscatter based fiber optic distributed temperature system (DTS) technology [8421-358]

J. Bertrand, ANDRA (France); R. Morice, O. Beaumont, LNE (France); J. P. Dubois, ANDRA (France) 
8421 BB Resolution enhancement in Brillouin optical correlation domain analysis by differential lock-in detection [8421-372]

J. H. Jeong, Korea Institute of Science and Technology (Korea, Republic of) and Hanyang Univ. (Korea, Republic of); K. Lee, Korea Institute of Science and Technology (Korea,

Republic of); K. Y. Song, Chung-Ang Univ. (Korea, Republic of); J.-M. Jeong, Hanyang Univ. (Korea, Republic of); S. B. Lee, Korea Institute of Science and Technology (Korea, Republic of)

8421 BC Optical monitoring of curing process of concrete with plastic optical fibers [8421-385] L. Ferreira, Univ. de Aveiro (Portugal); P. Antunes, Univ. de Aveiro (Portugal) and Instituto de Telecomunicações (Portugal); H. Varum, Univ. de Aveiro (Portugal); P. André, Univ. de Aveiro (Portugal) and Instituto de Telecomunicações (Portugal)

$8421 \mathrm{BD}$ Towards the simultaneous monitoring of load and damage in aircraft structures using fiber Bragg grating sensors [8421-402]

G. G. Xiao, H. Guo, National Research Council Canada (Canada); N. Mrad, Dept. of National Defence (Canada); B. Rocha, Z. Sun, National Research Council Canada (Canada)

$8421 \mathrm{BE}$ Investigation on upper limit of dynamic range of fiber optic interferometric sensors base on the digital heterodyne demodulation scheme [8421-419]

N. Zhang, Z. Meng, W. Rao, S. Xiong, National Univ. of Defense Technology (China)

$8421 \mathrm{BF} \quad$ A hybrid fiber-optic sensor system for multi-stress monitoring of high-voltage power transformer [8421-427]

H. Kim, Chonbuk National Univ. (Korea, Republic of); H. Park, Electronics and Telecommunications Research Institute (Korea, Republic of); M. Song, Chonbuk National Univ. (Korea, Republic of)

8421 BG Analysis of fiber optic sensor application to precursory acoustic signals detection in rockfall events [8421-434]

L. Schenato, Italian National Research Council (Italy); L. Palmieri, L. Vianello, Univ. of Padova (Italy); G. Marcato, Italian National Research Council (Italy); G. Gruca, T. van de Watering, D. Iannuzzi, Vrije Univ. (Netherlands); A. Pasuto, Italian National Research Council (Italy); A. Galtarossa, Univ. of Padova (Italy)

$8421 \mathrm{BH} \quad$ A novel self-healing optical fiber sensor network [8421-455] J. He, Z. Zhou, J. Ou, Dalian Univ. of Technology (China)

$8421 \mathrm{BI} \quad$ A novel noise suppression method for white light extrinsic Fabry-Perot interferometric fiberoptic pressure sensor in heavy oil thermal recovery downhole environment [8421-480] Q. Zou, Tsinghua Univ. (China); S. Dou, C. Hu, Y. Pan, China National Petroleum Corp. (China); S. Xie, W. Wang, M. Zhang, Y. Liao, Tsinghua Univ. (China)

8421 BJ Condition monitoring of wind turbine blades with FBG sensors [8421-491] H. Kang, D. Kim, M. Song, Chonbuk National Univ. (Korea, Republic of)

8421 BK Scintillating optical fibre sensor for radiotherapy dosimetry [8421-504] D. McCarthy, S. O'Keeffe, Univ. of Limerick (Ireland); P. Woulfe, J. Cronin, Galway Clinic (Ireland); E. Lewis, Univ. of Limerick (Ireland) 
$8421 \mathrm{BL} \quad$ Field trials of fiber Bragg grating settlement sensors in high-speed railways [8421-506]

X. Lu, Y. Gong, X. Zheng, L. Du, Y. Wu, D. Li, L. Liu, Y. Yao, S. Xiao, Z. Deng, Y. Rao, Univ. of Electronic Science and Technology of China (China)

8421 BM Comparison of strain sensitivities of free and attached FBG strain sensors [8421-516]

J. Roths, Munich Univ. of Applied Sciences (Germany); L. Aulbach, A. Wilfert, P. Kratzer, F. Jülich, R. Kuttler, Technische Univ. München (Germany)

$8421 \mathrm{BN}$ Study of all-fiber optic anemometer and wind direction sensor [8421-568]

J. Ni, C. Wang, T. Liu, Y. Zhao, J. Wang, Z. Sun, X. Zhang, Shandong Academy of Sciences (China)

Author Index 


\title{
Conference Committees
}

\author{
Conference Chairs
}

Yanbiao Liao, Tsinghua University (China)

Conference Co-Chairs

David D. Sampson, University of Western Australia (Australia)

Ryozo Yamauchi, Fujikura Ltd. (Japan)

Technical Programme Committee Chair

Wei Jin, The Hong Kong Polytechnic University (Hong Kong, China)

Technical Programme Committee Co-Chairs

Youngjoo Chung, Gwangju Institute of Science \& Technology

(Korea, Republic of)

Kentaro Nakamura, Tokyo Institute of Technology (Japan)

Yunjiang Rao, University of Electronic Science and Technology (China)

International Steering Committee

Wojtek J. Bock, Université du Québec en Outaouais (Canada)

Youngjoo Chung, Gwangju Institute of Science \& Technology

(Korea, Republic of)

Wei Jin, The Hong Kong Polytechnic University (Hong Kong, China)

Julian D. C. Jones, Herriot-Watt University (United Kingdom)

Hypolito José Kalinowski, Federal University of Technology, Parana (Brazil)

Yanbiao Liao, Tsinghua University (China)

José M. López-Higuera, Universidad de Cantabria (Spain)

Alexis Mendez, MCH Engineering, Inc. (United States)

David D. Sampson, University of Western Australia (Australia)

Glen A. Sanders, NxtPhase Inc. (United States) and Honeywell Inc. (United States)

Nobuaki Takahashi, National Defense Academy (Japan)

Luc Thévenaz, École Polytechnique Fédérale de Lausanne

(Switzerland)

Reinhardt Willsch, IPHT Jena (Germany)

Ryozo Yamauchi, Fujikura Ltd. (Japan) 
International Honorary Committee

Jacques Albert

Thomas Bosselmann

Rick Claus

Brian Culshaw, Chair

John Dakin

Tony Dandridge

Gordon Day

Tom Giallorenzi

Masimitrsu Haruna

Kazuo Hotate

David Jackson

Alan Kersey

Ralph Kersten

Byoung Yoon Kim

Herve Lefevre

Anna Mignani

Alan Rogers

Eric Udd

Marc Voet

Technical Programme Committee

Jacques Albert, Carleton University (Canada)

Ole Bang, Technical University of Denmark (Denmark)

Xiaoyi Bao, University of Ottawa (Canada)

Francis Berghmans, Vrije Universiteit Brussel (Belgium)

Gabriele Bolognini, IMM Institute, National Research Council (Italy)

John Canning, The University of Sydney (Australia)

James H. Cole, Naval Research Laboratory (United States)

Stephen Collins, Victoria University (Australia)

Geoffrey Cranch, Naval Research Laboratory (United States)

Michel Digonnet, Stanford University (United States)

Wolfgang Ecke, IPHT Jena (Germany)

Gerald Farrell, Dublin Institute of Technology (Ireland)

Pierre Ferdinand, CEA List (France)

Young-Geun Han, Hanyang University (Korea, Republic of)

Juan Hernandez Cordero, Universidad Nacional Autónoma de México (Mexico)

Leszek R Jaroszewicz, Military University of Technology (Poland)

Wei Jin, The Hong Kong Polytechnic University (China)

Paul Lefebvre, LxData (Canada)

Robert Liebermann, Information Operations Squadron (United States)

Manuel López-Amo, Universidad Publica de Navarra (Spain)

Cicero Martelli, Universidade Tecnológica Federal do Paraná (Brazil)

Stephen Mihailov, Communications Research Centre (Canada)

Hideaki Murayama, The University of Tokyo (Japan) 
Kazuhide Nakajima, NTT (Japan)

Kentaro Nakamura, Tokyo Institute of Technology (Japan)

Kyunghwan Oh, Yonsei University (Korea, Republic of)

Yunjiang Rao, University of Electronic Science and Technology

(China)

Takanori Saitoh, Anritsu (Japan)

Akira Sakamoto, Fujikura Ltd. (Japan)

Jose L. Santos, INESC Porto (Portugal)

Ralph P. Tatam, Cranfield University (United Kingdom)

Pedro Torres Trujillo, Universidad Nacional de Colombia, Sede Medellin (Colombia)

Moshe Tur, Tel Aviv University (Israel)

Anbo Wang, Virginia Tech, Blacksburg (United States)

David Webb, Aston University (United Kingdom)

Libo Yuan, Harbin Engineering University (China)

Local Organising Committee

Qian Tian, Tsinghua University, Beijing (China)

Yuwen Qin, National Natural Science Foundation of China, Beijing (China)

Yi Luo, Tsinghua University, Beijing (China)

Wei Wang, China Academy of Aerospace Electronics Technology, Beijing (China)

Min Zhang, Tsinghua University, Beijing (China)

Hoi Lut Ho, The Hong Kong Polytechnic University (Hong Kong, China)

Jun Yang, Harbin Engineering University, Harbin (China)

Yuanhong Yang, BaiHang University, Beijing (China)

Yulin Li, Wuhan Photonics Technology Ltd. Company (China)

Shurong Lai, Tsinghua University, Beijing (China)

Peter Chan, Amonics Ltd. (Hong Kong, China)

Xin Shi, The Hong Kong Polytechnic University

(Hong Kong, China)

Session Chairs

Fiber Optic Gyro I: 35 Anniversary Workshop

Glen A. Sanders, Honeywell (United States)

Fiber Optic Gyro II: 35 Anniversary Workshop

Kazuo Hotate, University of Tokyo (Japan)

Fiber Optic Gyro III: 35 Anniversary Workshop

Michel Digonnet, Stanford University (United States)

Fiber Optic Gyro IV: 35 Anniversary Workshop

Byoung Yoon Kim, KAIST (Korea, Republic of) 
Special Workshop on Industrial Progress, Commercial Systems, and Field Tests I

Brian Culshaw, University of Strathclyde (United Kingdom)

David Sampson, University of Western Australia (Australia)

Special Workshop on Industrial Progress, Commercial Systems, and Field Tests II

Jose M. Lopez-Higuera, Universidad de Cantabria (Spain)

Ryozo Yamauchi, Fujikura Ltd. (Japan)

Special Workshop on Industrial Progress, Commercial Systems, and Field Tests III

Hypolito Jose Kalinowski, Federal University of Technology (Brazil)

Youngjoo Chung, Gwangju Institute of Science \& Technology

(Korea, Republic of)

Special Workshop on Industrial Progress, Commercial Systems, and Field Tests IV

Julian D. C. Jones, Herriot-Watt University (United Kingdom)

Nobuaki Takahashi, National Defense Academy (Japan)

Plenary Session

Yanbiao Liao, Tsinghua University (China)

Physical and Mechanical Sensors I

Kentaro Nakamura, Tokyo Institute of Technology (Japan)

Leszek R. Jaroszewicz, Military University of Technology (Poland)

Micro- and Nano-structured Fiber Sensors I

Yunjiang Rao, University of Electronic Science and Technology

(China)

Jose L. Santo, INESC Porto (Portugal)

Distributed Sensing I

Xiaoyi Bao, University of Ottawa (Canada)

Hideaki Murayama, University of Tokyo (Japan)

Physical and Mechanical Sensors II

Gabriele Bolognini, IMM Institute, National Research Council (Italy)

Gang-Ding Peng, The University of New South Wales (Australia)

Micro- and Nano-structured Fiber Sensors II

Young-Guen Han, Hanyang University (Korea, Republic of)

Yi-Ping Wang, Shenzhen University (China) 
Slow and Fast Light, and Other Emerging Technologies

John Canning, The University of Sydney (Australia)

Kazuhide Nakajima, NTT (Japan)

Smart Structures and Sensor Multiplexing

Pierre Ferdinand, CEA List (France)

Akira Sakamoto, Fujikura Ltd. (Japan)

Biomedical and Chemical Sensors I

David Webb, Aston University (United Kingdom)

Tong-Yu Liu, Laser Institute of Shandong Academy of Sciences (China)

Biomedical and Chemical Sensors II

Wojtek J. Bock, Université du Québec en Outaouais (Canada)

Kyunghwan Oh, Yonsei University (Korea, Republic of)

Fiber Grating Sensors

Wolfgang Ecke, IPHT Jena (Germany)

Bai-Ou Guan, Jinan University (China)

Distributed Sensing II

Luc Thévenaz, Ecole Polytechnique Fédérale de Lausanne (Switzerland)

Cicero Martelli, Federal University of Technology (Brazil)

Sensor Application and Field Tests

Reinhardt Willsch, IPHT Jena (Germany)

Manuel Lopez-Amo, Universidad Pública de Navarra (Spain)

Presentation of Best Student Paper Prizes

Youngjoo Chung, Gwangju Institute of Science \& Technology

(Korea, Republic of)

Libo Yuan, Harbin Engineering University (China)

Closing Ceremony

Yanbiao Liao, Tsinghua University (China)

Jose M. Lopez-Higuera, Universidad de Cantabria (Spain) 
Proc. of SPIE Vol. $8421842101-48$

Downloaded From: https://www.spiedigitallibrary.org/conference-proceedings-of-spie on 26 Apr 2023 Terms of Use: https://www.spiedigitallibrary.org/terms-of-use 


\section{Introduction}

It gives us great pleasure to welcome you to the 22nd International Conference on Optical Fiber Sensors (OFS-22), which will be held in Beijing from 15-19 October 2012. The OFS series is acknowledged as the world's leading conference on all topics related to fiber-optic, guided-wave, and optical sensing devices, systems, theories, and techniques for research and applications. The first OFS was held in London in 1983. Since then it is held approximately every eighteen months, rotating between the Americas, Europe, and Asia/Pacific. This is the first time that China hosts the OFS conference.

The programme for OFS-22 includes 34 invited talks: nine of these are for a special workshop to celebrate the $35^{\text {th }}$ anniversary of fiber optic gyros; 14 will be presented at a workshop on Industrial Progress, Commercial Systems, and Field Tests; 11 others are dispersed throughout the technical sessions, all providing upto-date description of key areas of OFS technology and applications by experts from around the world. Our plenary speaker is Tuan Vo-Dinh, who will speak on Optical Nanosensors and Nanoprobes: From Single-Cell Exploration to Medical Diagnostics.

The programme also includes 382 contributed papers from 30 countries. These papers will be presented in 12 oral sessions and three poster sessions. 331 contributed papers are included in poster sessions. In addition, a session for postdeadline papers and a table-top exhibition are also included.

We are indebted to the members of the International Steering Committee and the International Honorary Committee for their assistance in preparing for this conference. We would particularly like to thank the members of the Technical Programme Committee for rapidly and competently referring the large number of submissions and to the Local Organising Committee for their hard work to make this conference a success.

We hope you enjoy the conference as well as the City of Beijing at its 'golden' autumn season.

\section{Yanbiao Liao \\ Wei Jin \\ David D. Sampson \\ Ryozo Yamauchi \\ Youngjoo Chung \\ Kentaro Nakamura \\ Yunjiang Rao}


Proc. of SPIE Vol. $8421842101-50$

Downloaded From: https://www.spiedigitallibrary.org/conference-proceedings-of-spie on 26 Apr 2023 Terms of Use: https://www.spiedigitallibrary.org/terms-of-use 


\section{Editors' Note}

All contributed papers in their entirety (i.e., not merely an abstract or extract) were peer-reviewed for their significance, innovation, and quality by independent members of the Technical Programme Committee, and then rated. 
Proc. of SPIE Vol. $8421842101-52$

Downloaded From: https://www.spiedigitallibrary.org/conference-proceedings-of-spie on 26 Apr 2023 Terms of Use: https://www.spiedigitallibrary.org/terms-of-use 